\title{
STABILITY INDICATING HPLC METHOD FOR THE QUANTIFICATION OF CEFIXIME, ORNIDAZOLE AND MOXIFLOXACIN IN SOLID DOSAGE FORMS
}

\author{
Suresh Kumar Palacharla and G. V. Krishna Mohan \\ Department of Chemistry, K.L. University, Guntur, AP, India \\ *E-mail: palacharla.suresh@gmail.com
}

\begin{abstract}
Cefixime is used for bacterial infections recovery, Ornidazole is used as antibiotic for protozoan infections and Moxifloxacin is also an antibiotic for multiple bacterial infections. Accurate, simple and precise HPLC method was developed for the determination of Cefixime, Ornidazole and Moxifloxacin in the tablet pharmaceutical dosage form. The RP-HPLC method was developed and validated with precision, specificity, accuracy, ruggedness, robustness and linearity. Chromatographic conditions are mobile phase A: $6.8 \mathrm{~g} \mathrm{KH}_{2} \mathrm{PO}_{4}$ in $1000 \mathrm{ml}$ water and

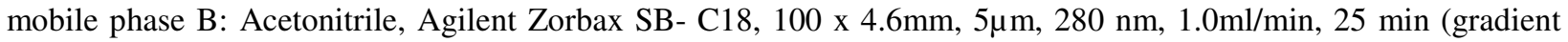
program: mobile phase B at 0min 5\%, 5min 5\%, $10 \mathrm{~min} 15 \%, 14 \mathrm{~min} \mathrm{15 \% ,17} \mathrm{min} 35 \%, 20 \mathrm{~min} 5 \%$ and $25 \mathrm{~min} 5 \%$. All validation results showed the accuracy results and \% RSD for test area, \%assay values were also within the limits. This HPLC method can be used to analyze the regular product quality control purpose.
\end{abstract}

Keywords: Cefixime, Ornidazole, Moxifloxacin, Method development and validation

(C) RASĀYAN. All rights reserved

\section{INTRODUCTION}

Cefixime is used to treat bacterial infections includes otitis media, pneumonia, strep throat, urinary tract infections, gonorrhoea and lyme disease. ${ }^{1-2}$ Cefixime was approved in USA IN 1989. It is marketed under many trade names such as texit (Apex, Cef-3 and Denvar. ${ }^{3-5}$ Cefixime chemical formula is $\mathrm{C} 16 \mathrm{H} 15 \mathrm{~N} 5 \mathrm{O} 7 \mathrm{~S} 2$ and molecular mass is $453.452 \mathrm{~g} / \mathrm{mol}$. Ornidazole is used as antibiotic for some protozoan infections. ${ }^{6-7}$ This drug can be used for crohn's disease after bowel resection. ${ }^{8-10}$ Moxifloxacin is an antibiotic used to treat the number of bacterial infections. ${ }^{11}$ These infections include pneumonia ${ }^{12}$, conjunctivitis ${ }^{13}$, endocarditis ${ }^{14}$, tuberculosis and sinusitis. ${ }^{15}$ Moxifloxacin was approved in the USA in 1999 and it is on the WHOs list of essential medicines.

Cefixime and Ornidazole were available in combined tablet dosage form with Cefixime $200 \mathrm{mg}$ and Ornidazole $500 \mathrm{mg}$ or Cefixime $50 \mathrm{mg}$ and Ornidazole $125 \mathrm{mg}$. Cefixime and Moxifloxacin were available in combined tablet dosage form with Cefixime $400 \mathrm{mg}$ and Moxifloxacin $400 \mathrm{mg}$. Cefixime, Ornidazole and Moxifloxacin chemical structures were represented in Fig.-1.<smiles>C=CC1=C(C(=O)O)N2C(=O)[C@H](NC(=O)/C(=N/OCC(=O)O)c3csc(N)n3)[C@H]2SC1</smiles>

Cefixime<smiles>Cc1ncc([N+](=O)[O-])n1CC(O)CCl</smiles>

Ornidazole<smiles>COc1c(N2C[C@H]3NCCC[C@@H]3C2)c(F)cc2c(=O)c(C(=O)O)cn(C3CC3)c12</smiles>

Moxifloxacin

Fig.-1: Chemical Structures of Cefixime, Ornidazole and Moxifloxacin

Rasayan J. Chem., 11(4), 1696-1714(2018)

http://dx.doi.org/10.31788/RJC.2018.1144093 
RASĀYAN J. Chem.

Vol. 11 | No. 4 |1696 - 1714| October - December | 2018

Literature survey reveals the few reported methods on Cefixime and Ornidazole on UV spectroscopy methods ${ }^{16-17}$ and some methods were published on HPLC. ${ }^{18}$ Cefixime and Moxifloxacin were determined by UV spectrophotometric method ${ }^{19-22}$ and some of the authors were published on HPLC instrument. ${ }^{23-28}$

\section{Materials}

\section{EXPERIMENTAL}

Agilent makes alliance HPLC instrument equipped with a pump, detector, auto sampler, column oven and Empower software. Agilent makes Zorbax Eclipse SB C18 100mm column was purchased from a local distributor in Hyderabad. Analytical grade $\mathrm{K}_{2} \mathrm{HPO}_{4}$ buffer salt and ortho-phosphoric acid were used purchased from Merck India Pvt. Limited. Gradient grade acetonitrile and methanol were purchased from Qualigens chemical supplier from Hyderabad.

\section{Methods}

Reverse phase HPLC method was optimized to determine the Cefixime, Ornidazole and Moxifloxacin in solid dosage formulations. Optimized method was validated with precision, linearity, accuracy, limit of detection, limit of quantification, ruggedness and robustness. Chromatographic conditions were discussed below,

\section{HPLC conditions}

$\begin{array}{ll}\text { Column } & : \text { Agilent } \text { Zorbax SB-C18, } 100 \times 4.6 \mathrm{~mm}, 5 \mu \mathrm{m} \\ \text { Flow rate } & : 1.0 \mathrm{~mL} / \text { minute } \\ \text { Detection } & : 280 \mathrm{~nm} \\ \text { Injection Volume } & : 20 \mu \mathrm{L} \\ \text { Column temperature } & : 30^{\circ} \mathrm{C} \\ \text { Analysis time } & : 25 \text { minutes }\end{array}$

\section{Mobile Phase-A}

$6.8 \mathrm{~g}$ of di-potassium hydrogen phosphate $\left(\mathrm{KH}_{2} \mathrm{PO}_{4}\right)$ weighed and transferred into $1000 \mathrm{~mL}$ of water and sonicated to dissolve. The resulting solution was degassed through a $0.45 \mu \mathrm{m}$ membrane filter using a vacuum pump.

\section{Mobile Phase-B}

Gradient grade acetonitrile was used as mobile phase B and degassed through the $0.45 \mu$ filter.

\section{Diluent}

Mobile phase A and B were mixed in the ratio of 50:50 \% v/v and mixed well.

\section{Mobile Phase Elution Gradient Program}

\begin{tabular}{c|c|c}
\multicolumn{3}{|c}{ Table-1: Gradient Program } \\
\hline $\begin{array}{c}\text { Time } \\
\text { Minutes })\end{array}$ & $\begin{array}{c}\text { Mobile Phase-A } \\
(\% \mathrm{v} / \mathrm{v})\end{array}$ & $\begin{array}{c}\text { Mobile Phase-B } \\
(\% \mathrm{v} / \mathrm{v})\end{array}$ \\
\hline 0.00 & 95 & 5 \\
\hline 5.00 & 95 & 5 \\
\hline 10.00 & 85 & 15 \\
\hline 14.00 & 85 & 15 \\
\hline 17.00 & 68 & 32 \\
\hline 20.00 & 95 & 5 \\
\hline 25.00 & 95 & 5 \\
\hline
\end{tabular}




\section{Standard Stock Solution}

$50 \mathrm{mg}$ of Cefixime standard, $50 \mathrm{mg}$ Ornidazole standard and $50 \mathrm{mg}$ of Moxifloxacin were weighed accurately and transferred into a $100 \mathrm{~mL}$ volumetric flask. $50 \mathrm{~mL}$ of diluent was added to dissolve the contents and mixed well. Remaining volume was filled and mixed.

\section{Standard Solution Preparation}

$1.0 \mathrm{ml}$ of the standard stock solution was pipetted and transferred into $50 \mathrm{ml}$ class A volumetric flask and diluted with a diluent.

\section{Preparation of Cefixime and Ornidazole Sample Solution}

Randomly selected 20 tablets and weighed individually and calculated the average weight of one tablet and prepared the fine powder. Equivalent to $50 \mathrm{mg}$ of Cefixime and Ornidazole tablets powder was weighed and transferred into $100 \mathrm{~mL}$ volumetric flask. $50 \mathrm{ml}$ of diluent was added and dissolve the content by using handshake and sonication for 10 minutes. Further volume was diluted with a diluent. The stock solution was filtered with Whatman filter. $1 \mathrm{~mL}$ of the above solution was transferred into a 50 $\mathrm{mL}$ volumetric flask and diluted.

\section{Preparation of Cefixime and Moxifloxacin Sample Solution}

Randomly selected 20 tablets and weighed individually and calculated the average weight of one tablet and prepared the fine powder. Equivalent to $50 \mathrm{mg}$ of Cefixime and $50 \mathrm{mg}$ Moxifloxacin tablets powder was weighed and transferred into $100 \mathrm{~mL}$ volumetric flask. $50 \mathrm{ml}$ of diluent was added and dissolve the content by using handshake and sonication for 10 minutes. Further volume was diluted with a diluent. The stock solution was filtered with Whatman filter. $1 \mathrm{~mL}$ of the above solution was transferred into a 50 $\mathrm{mL}$ volumetric flask and diluted.

\section{System Suitability Limits}

All three peaks (Cefixime, Ornidazole and Moxifloxacin) in standard solution tailing factor should be not more than 2.0 and theoretical plates value should be more than 2000 . \%RSD for five replicate standard solutions area should be less than $2.0 \%$.

Percentage Assay Value Calculation $=$

Tarea X Tweight X 1 X 100 X 50 X Label claim X Potency

Sarea X 100 X 50 X Sweight X 1X Tablet weight X 100 X 100

In the above calculation formula, Tarea is Peak area from sample preparation; Sarea is Average peak area from standard solution; Tweight is the weight of standard taken in $\mathrm{mg}$; Sweight is the weight of the standard solution.

\section{HPLC Method Optimization}

\section{RESULTS AND DISCUSSION}

Method optimization was initiated based on the understanding of the molecules polarity, functional groups activity and reported literature. Solubility was checked in water with different $\mathrm{pH}$ levels, acetonitrile, methanol and mixed ratio solutions. UV spectroscopic nm was evaluated by scanning of the standard materials from $200 \mathrm{~nm}$ to $400 \mathrm{~nm}$. Based on the evaluation of UV spectroscopic results $280 \mathrm{~nm}$ has a maximum absorbance at all compounds. Further, HPLC method optimization was performed. Figure-2 represented the UV spectrum of Cefixime, Ornidazole and Moxifloxacin.

\section{HPLC Method Optimization Trial-1 Conditions}

1. $1.0 \mathrm{~g}$ of ammonium acetate in $1000 \mathrm{ml}$ of water used as a buffer

2. 2. Buffer as mobile phase A and acetonitrile as mobile phase B was eluted with a gradient program 
RASĀYAN J. Chem.

Vol. 11 | No. 4 |1696 - 1714| October - December | 2018

3. 3. Acetonitrile and acetonitrile $80: 20 \mathrm{v} / \mathrm{v}$ used as mobile phase $\mathrm{B}$

4. 4. Zorbax ODS $150 \times 4.6 \mathrm{~mm}, 5 \mu$ column

5. 5. Flow rate $1.0 \mathrm{ml} / \mathrm{min}, 30^{\circ} \mathrm{C}$ column temperature, $280 \mathrm{~nm}$

6. 6. Gradient program at 0 min $15 \%$ mobile phase B, at $10 \mathrm{~min} 25 \%$, at $18 \mathrm{~min} 40 \%$, at $22 \mathrm{~min}$ $40 \%$, at $23 \mathrm{~min} 15 \%$ and at $27 \mathrm{~min} 15 \%$

7. 7. Diluent: buffer and acetonitrile $50: 50 \mathrm{v} / \mathrm{v}$.
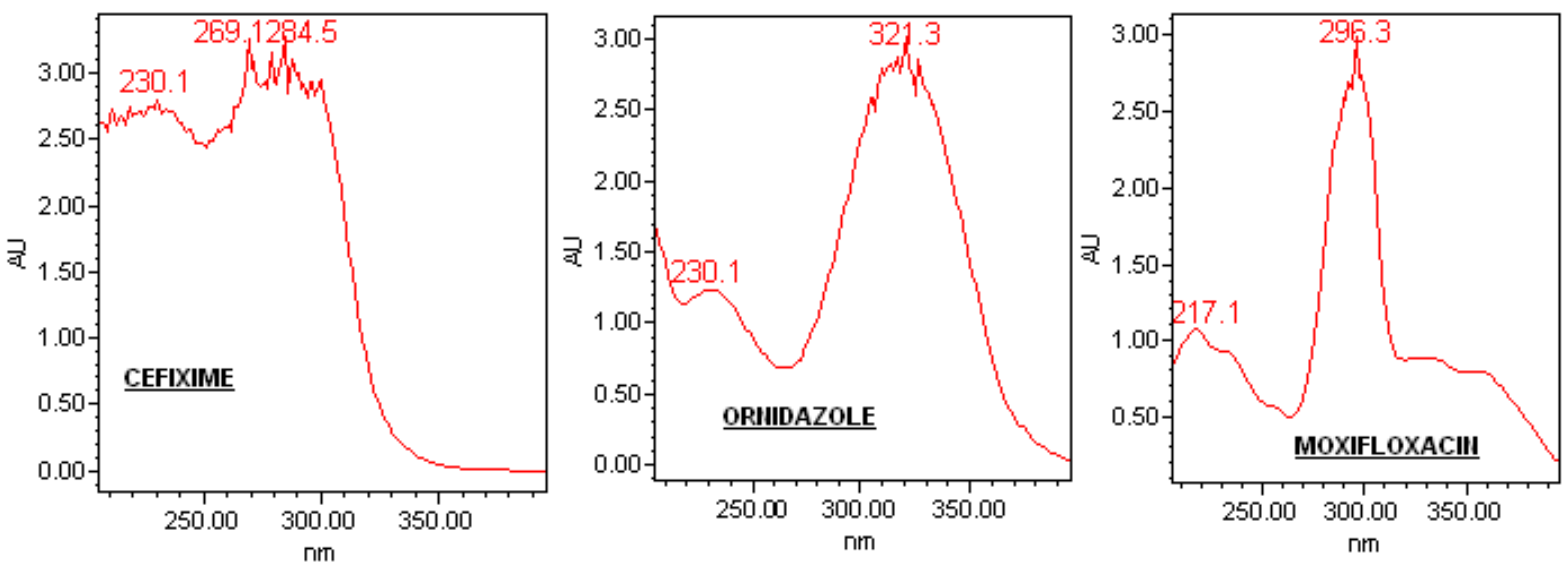

\section{Observation}

Fig.-2: UV Spectrum of Cefixime, Ornidazole and Moxifloxacin

All three peaks were eluted but Cefixime was eluted at $2.3 \mathrm{~min}$ and other components were eluted separately. Further optimization carried out by changing the mobile phase ratio. Cefixime, Ornidazole and Moxifloxacin individual samples were analyzed with the isocratic program with different mobile phase A and $\mathrm{B}$ ratios for elution confirmation and chromatograms were shown in Fig.-3 to 5 and development trial mixed sample chromatogram was represented in Fig.-6.

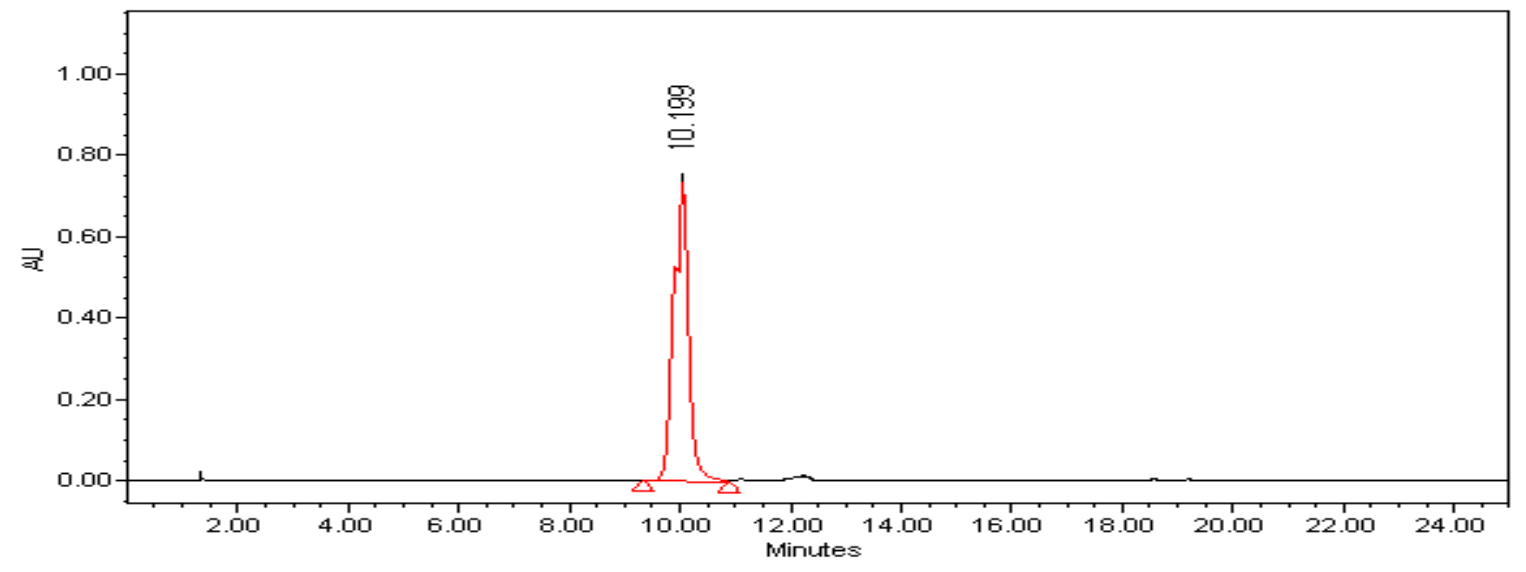

Fig.-3: Cefixime Chromatogram

\section{HPLC Method Optimization Trial-2}

\section{Conditions}

1. $6.8 \mathrm{~g}$ of $\mathrm{KH}_{2} \mathrm{PO}_{4}$ in $1000 \mathrm{ml}$ of water used as a buffer

2. Buffer as mobile phase $A$ and acetonitrile as mobile phase $B$ was eluted with a gradient program

3. Acetonitrile and acetonitrile $80: 20 \mathrm{v} / \mathrm{v}$ used as mobile phase B

4. Intertsil ODS-3 250x4.6mm, $5 \mu$ column

5. Flow rate $1.0 \mathrm{ml} / \mathrm{min}, 40^{\circ} \mathrm{C}$ column temperature, $280 \mathrm{~nm}$

6. Gradient program at $0 \min 25 \%$ mobile phase B, at $8 \min 25 \%$, at $15 \min 40 \%$, at $22 \min 40 \%$, at $23 \mathrm{~min} 25 \%$ and at $27 \mathrm{~min} 55 \%$

7. Diluent: buffer and acetonitrile 50:50 v/v. 
RASĀYAN J. Chem.

Vol. 11 | No. 4 |1696 - 1714| October - December | 2018

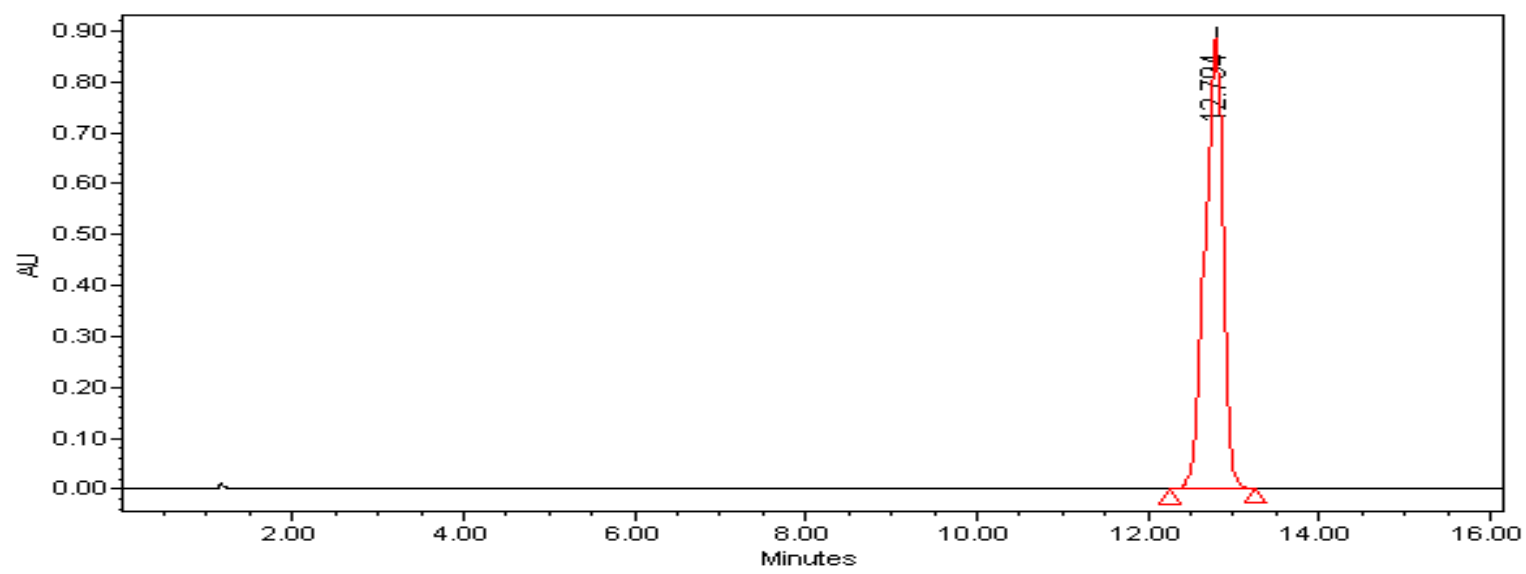

Fig.-4: Ornidazole Chromatogram

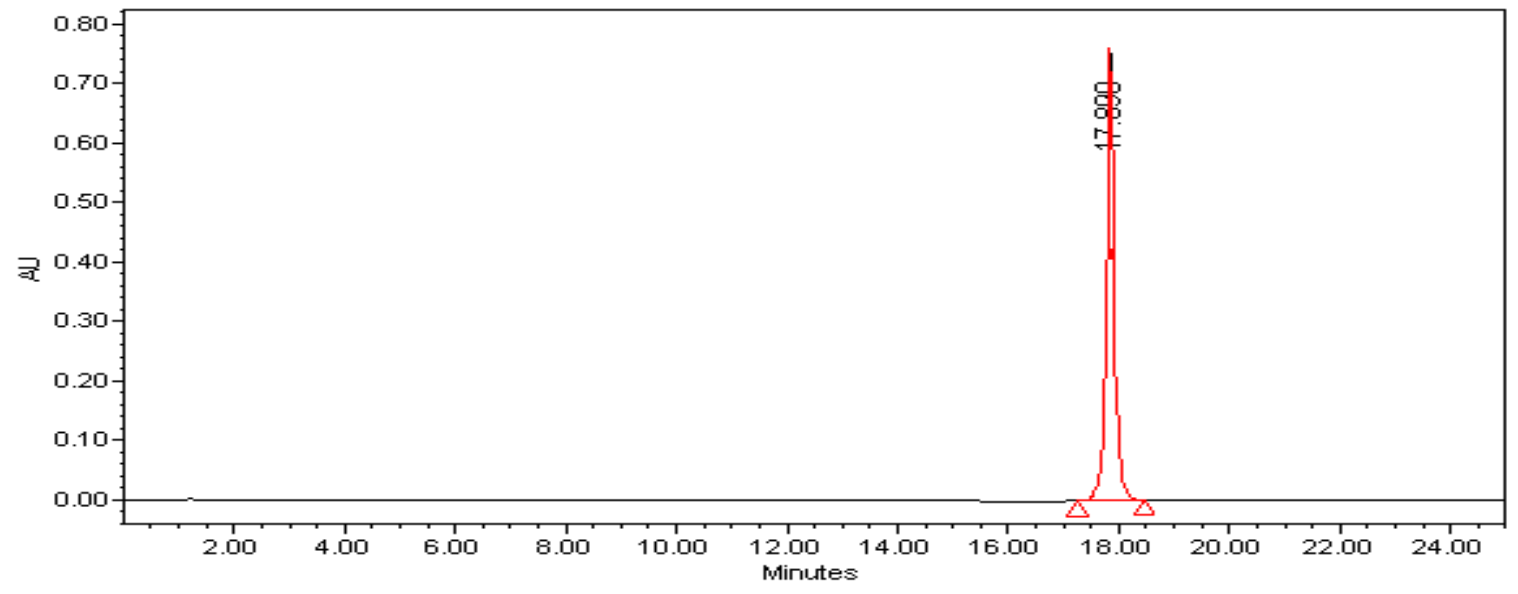

Fig.-5: Moxifloxacin Chromatogram

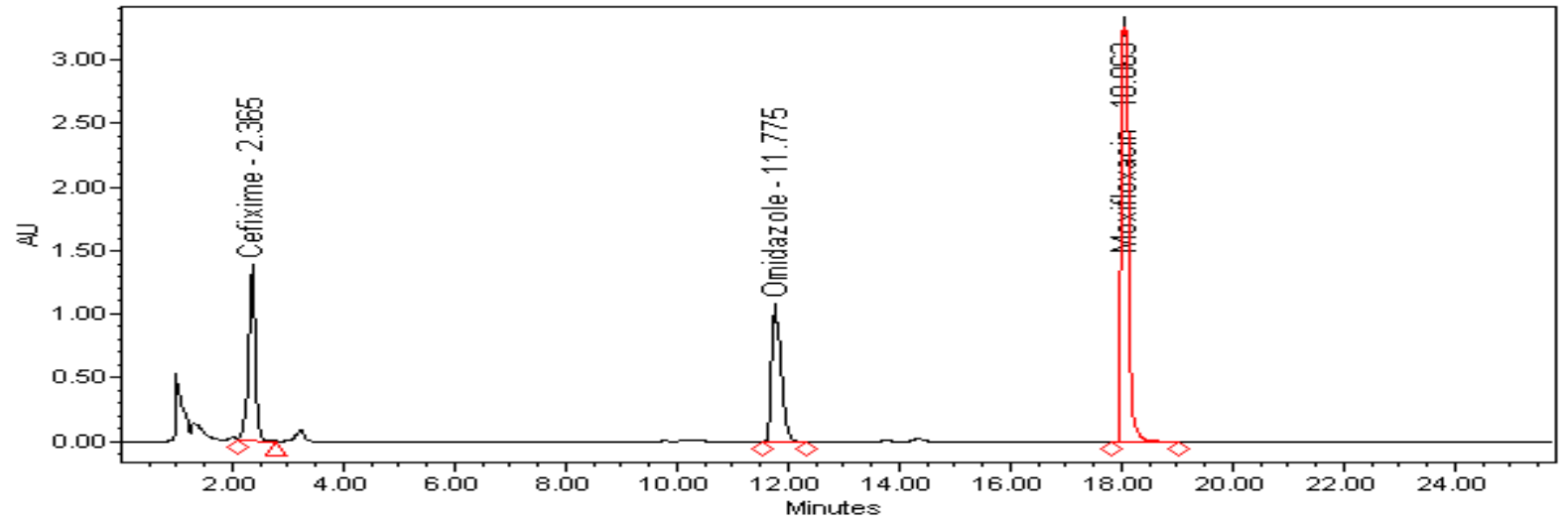

Fig.-6: Development Trial-1 Chromatogram

\section{Observation}

All three peaks were eluted but Cefixime peak shape was poor. Further optimization carried out by changing the HPLC column and gradient program. Development trial mixed sample chromatogram was represented in Fig.-7.

\section{HPLC Method Optimization Trial-3}

\section{Conditions}

1. $6.8 \mathrm{~g}$ of $\mathrm{KH}_{2} \mathrm{PO}_{4}$ in $1000 \mathrm{ml}$ of water used as a buffer 
RASĀYAN J. Chem.

Vol. 11 | No. 4 |1696 - 1714| October - December | 2018

2. Buffer as mobile phase $A$ and acetonitrile as mobile phase $B$ was eluted with a gradient program

3. Acetonitrile and acetonitrile $80: 20 \mathrm{v} / \mathrm{v}$ used as mobile phase B

4. Zorbax SB C18 100x4.6mm, 5 $\mu$ column

5. Flow rate $1.0 \mathrm{ml} / \mathrm{min}, 40^{\circ} \mathrm{C}$ column temperature, $280 \mathrm{~nm}$

6. Gradient program at $0 \mathrm{~min} 10 \%$ mobile phase $\mathrm{B}$, at $5 \mathrm{~min} 10 \%$, at $10 \mathrm{~min} 20 \%$, at $14 \mathrm{~min} 20 \%$, at $17 \min 40 \%$, at $20 \mathrm{~min}$ at $10 \%$ and at $25 \min 10 \%$

7. Diluent: buffer and acetonitrile 50:50 v/v.

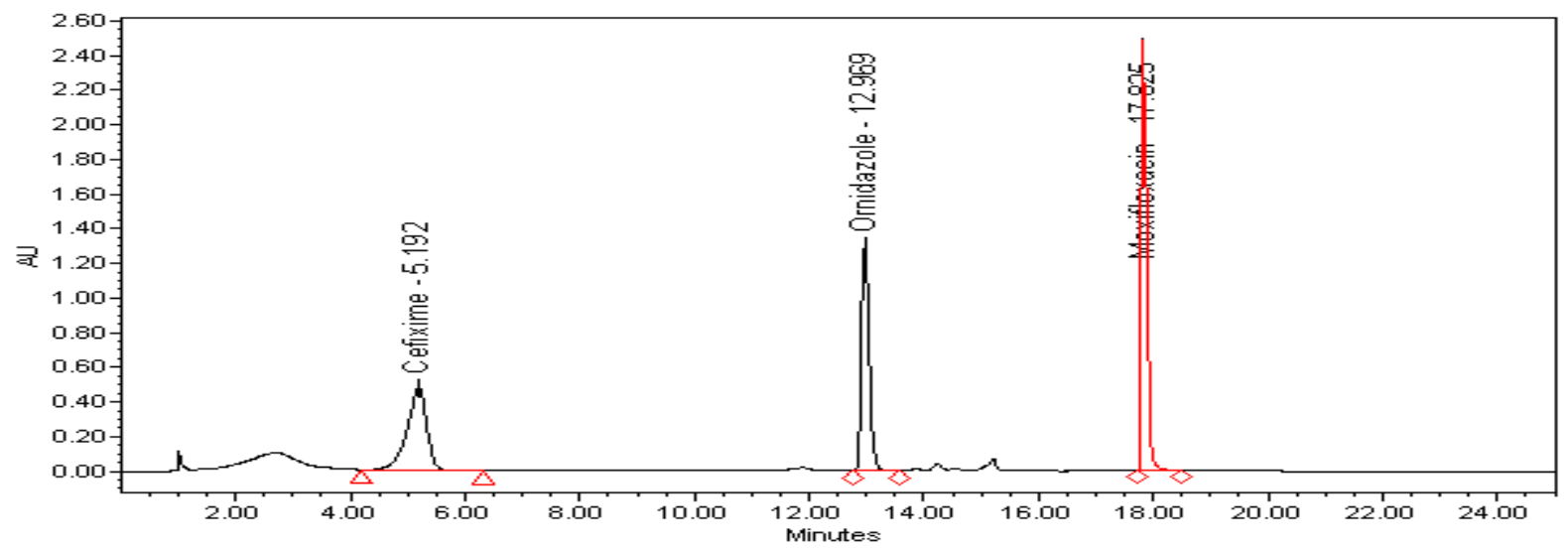

Fig.-7: Development Trial-2 Chromatogram

\section{Observation}

All three peaks were eluted and Cefixime and Ornidazole were eluted at $11.5 \mathrm{~min}$ and $12.4 \mathrm{~min}$ Moxifloxacin was eluted at $17.5 \mathrm{~min}$. Slight gradient program needs to modify to get more separation between Cefixime and Ornidazole. Development trial mixed sample chromatogram was represented in Fig.-8.

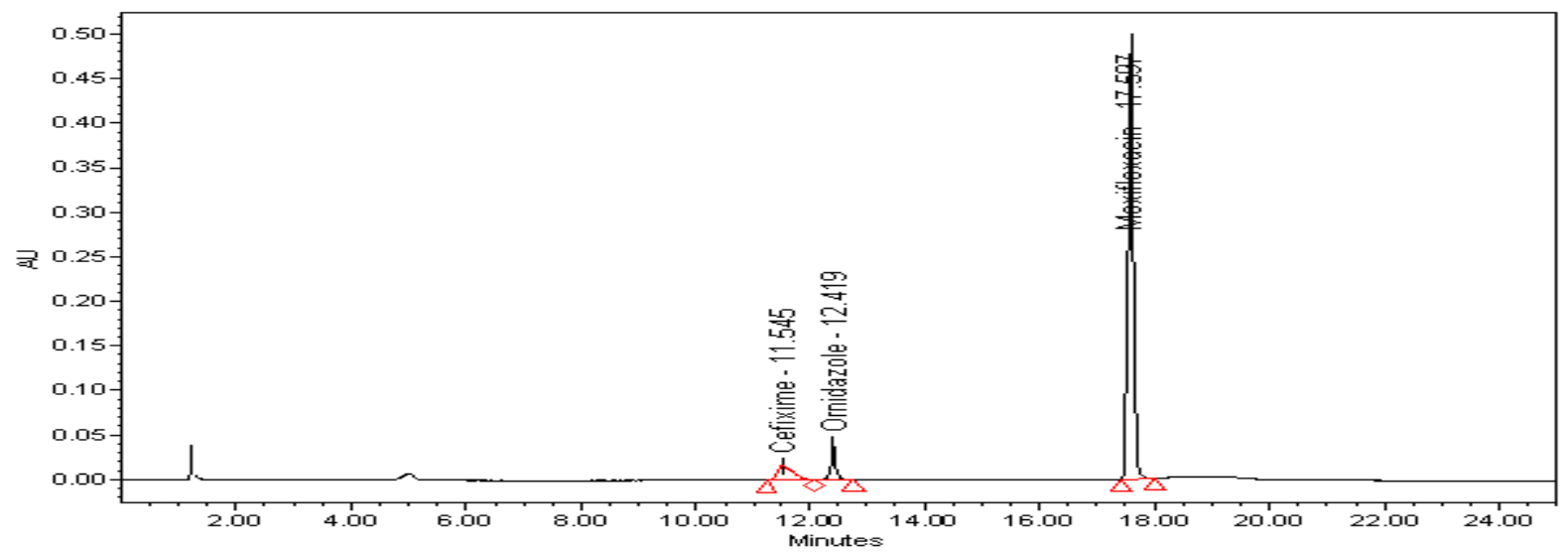

\section{Method Validation}

Fig.-8: Development Trial-3 Chromatogram

Optimized method was progressed for method validation as per the ICH Q2 guidance document. Precision, specificity, linearity, ruggedness, robustness and recovery studies were carried out.

\section{System Suitability}

Method system suitability was evaluated by preparing a fresh standard solution as per the finalized method mentioned in materials and method. Blank, placebo and five replicate standard solutions were injected in the HPLC system and system suitability parameters were evaluated. All system suitability results were satisfactory and all results were within the acceptable limits. Figure- 9 and 10 were 
RASĀYAN J. Chem.

Vol. 11 | No. 4 |1696 - 1714| October - December | 2018

represented the blank and placebo. Blank and standard overlay chromatogram were represented in Fig.11. Figure-12 represented the placebo and standard chromatogram. Figure-13 represented the standard solution chromatogram. All five replicate standard solution chromatogram was represented in Fig.-14. Figure-15 to 17 were represented the peak purity plot for Cefixime, Ornidazole and Moxifloxacin. Table2 represented the system suitability results.

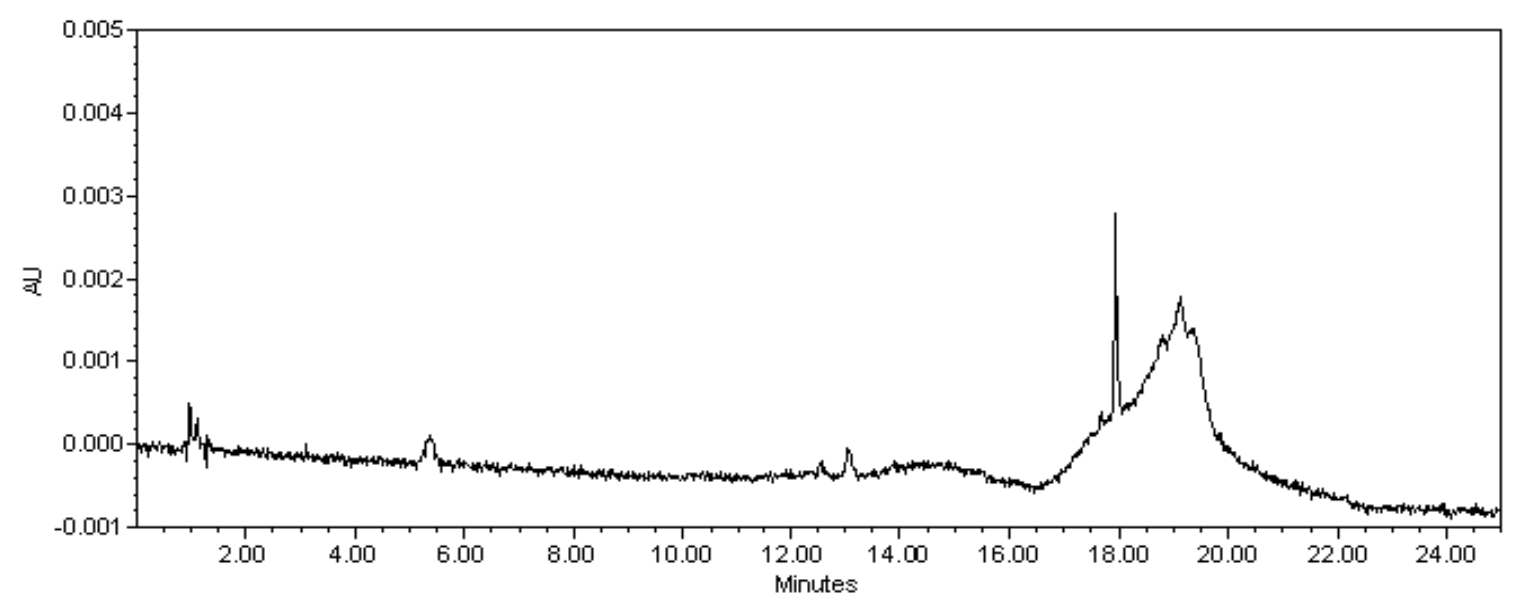

Fig.-9: Blank Chromatogram

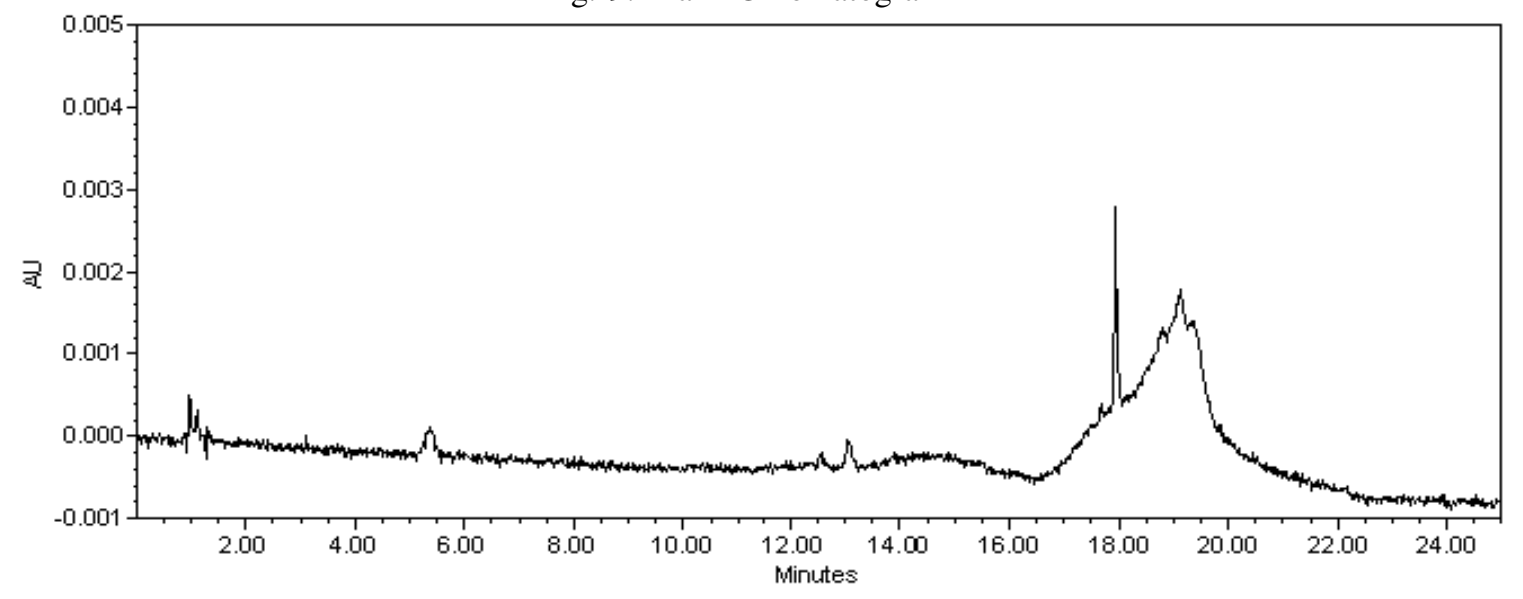

Fig.-10: Placebo Chromatogram

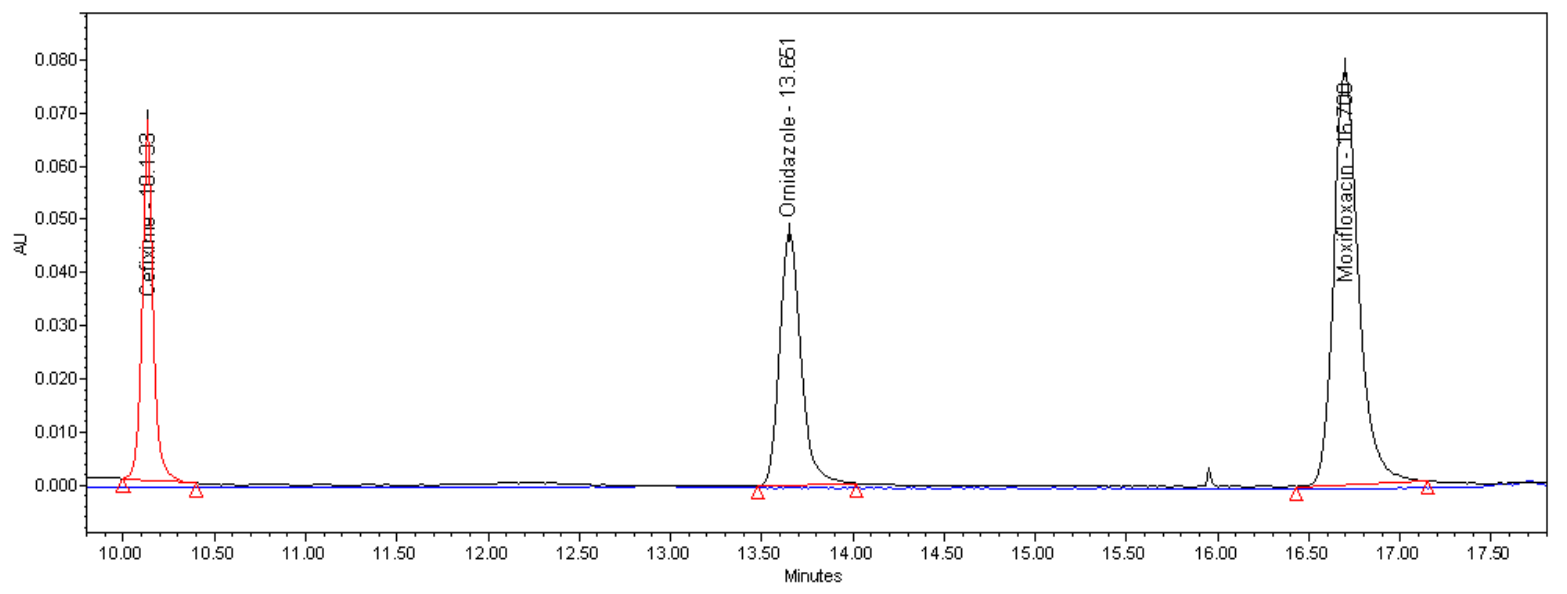

Fig.-11: Blank and Standard Overlay Chromatogram 
RASĀYAN J. Chem.

Vol. 11 | No. 4 |1696 - 1714| October - December | 2018

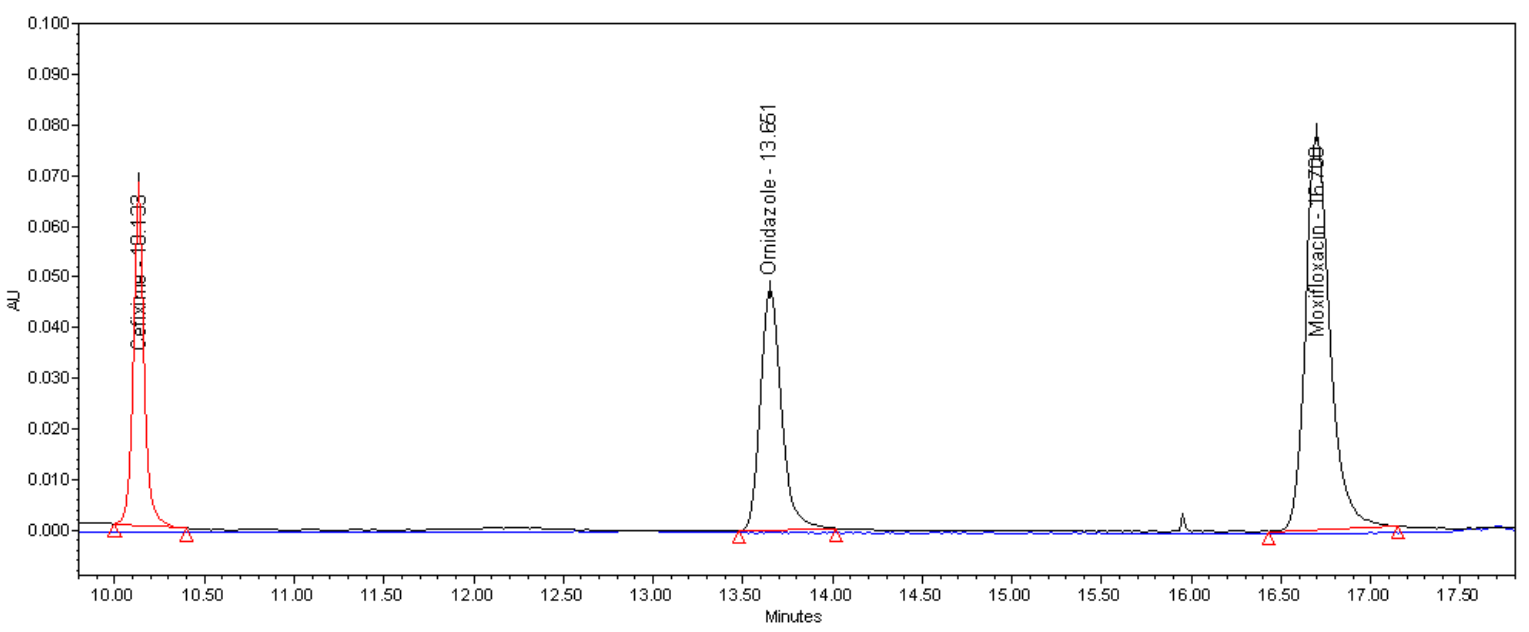

Fig.-12: Placebo and Standard Overlay Chromatogram

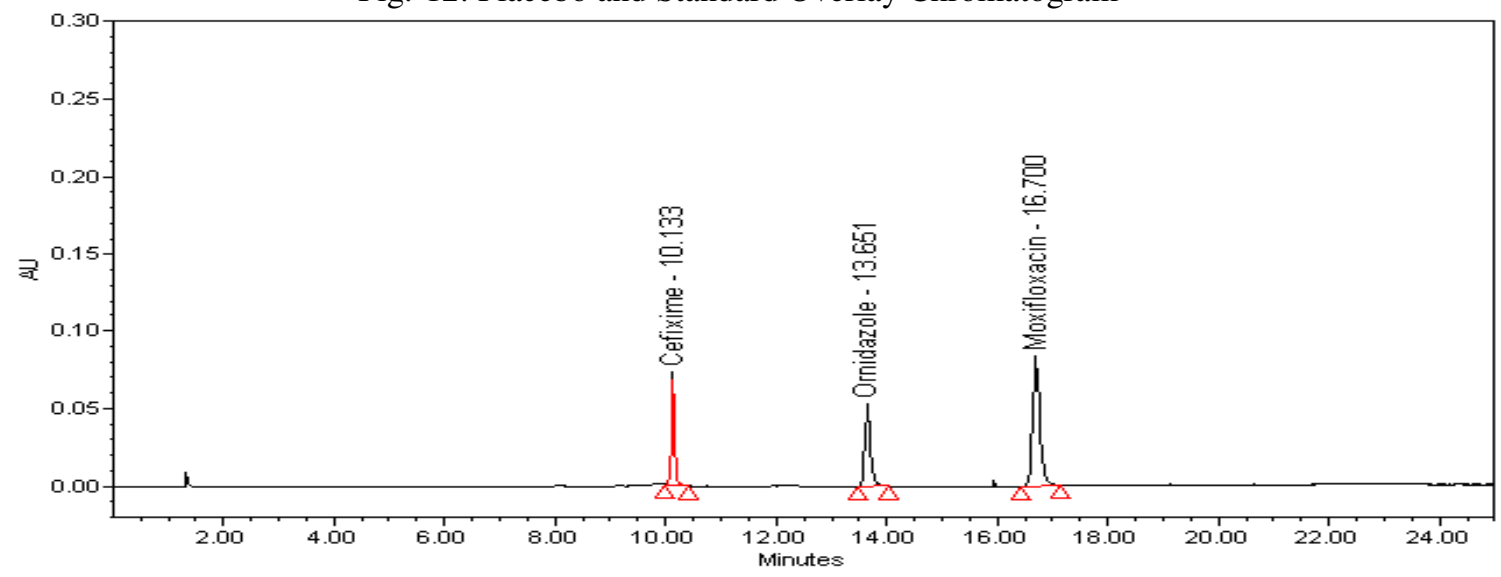

Fig.-13: Standard Solution Injection-1 Chromatogram
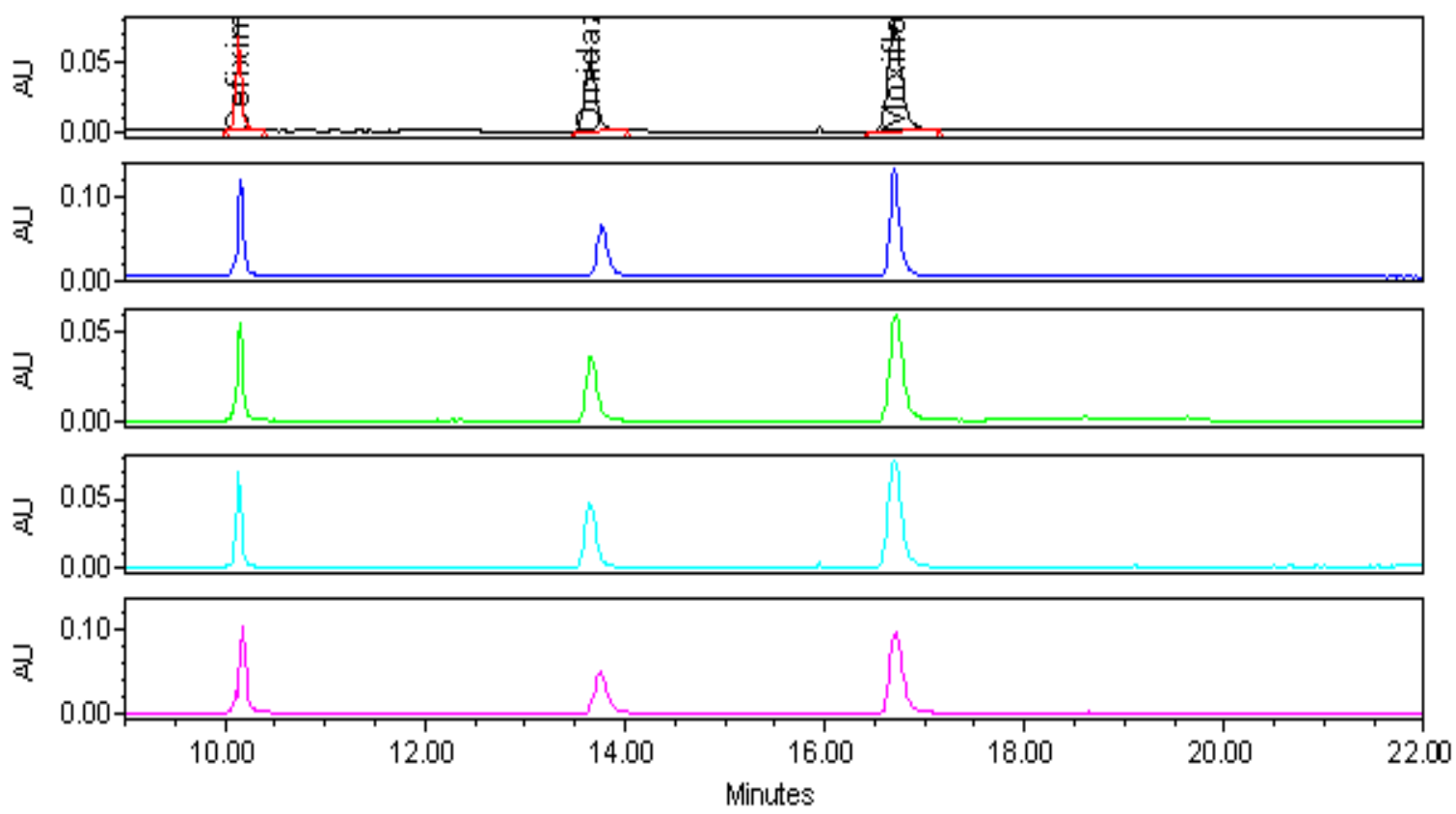

Fig.-14: Five Replicate Standard Solution Chromatogram 
RASĀYAN J. Chem.

Vol. 11 | No. 4 |1696 - 1714| October - December | 2018

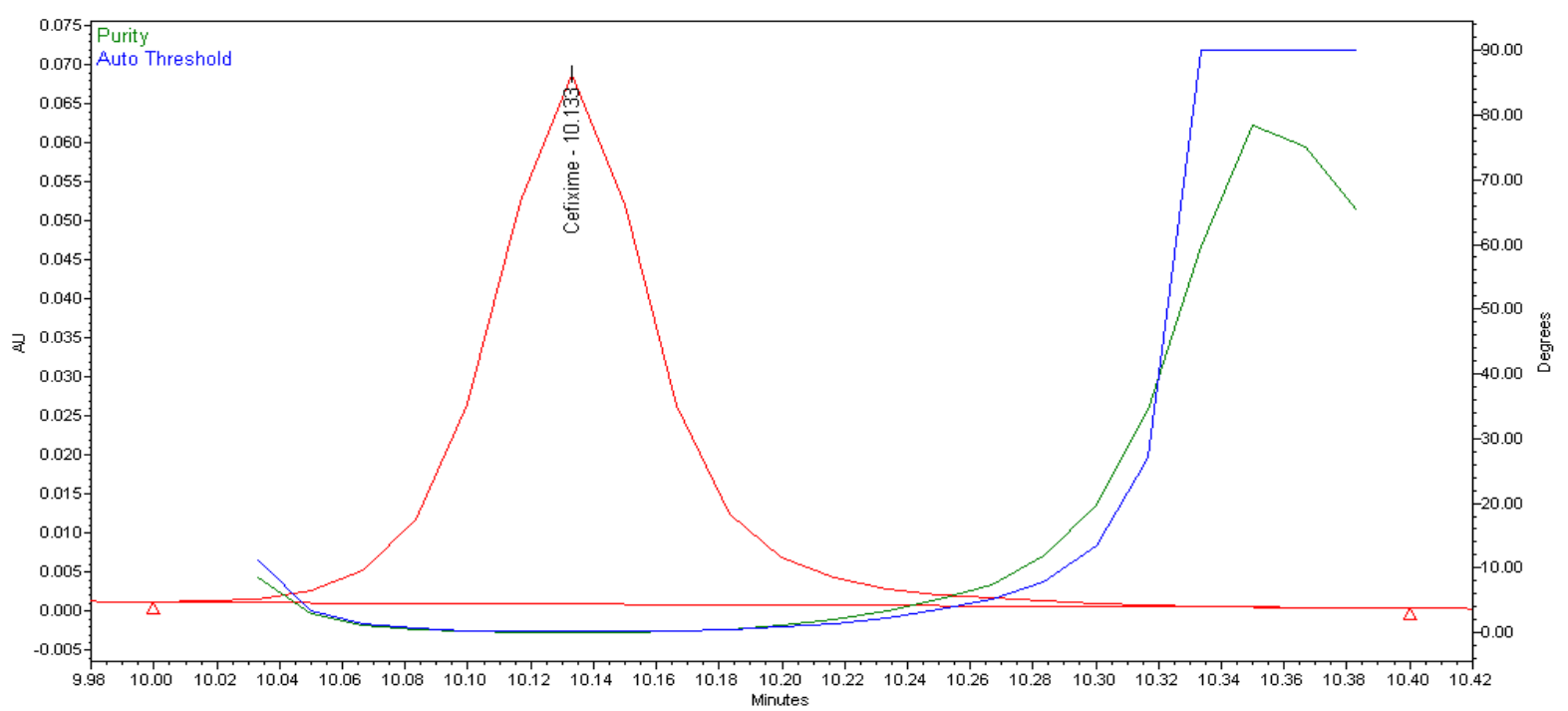

Fig.-15: Cefixime Peak Purity Plot

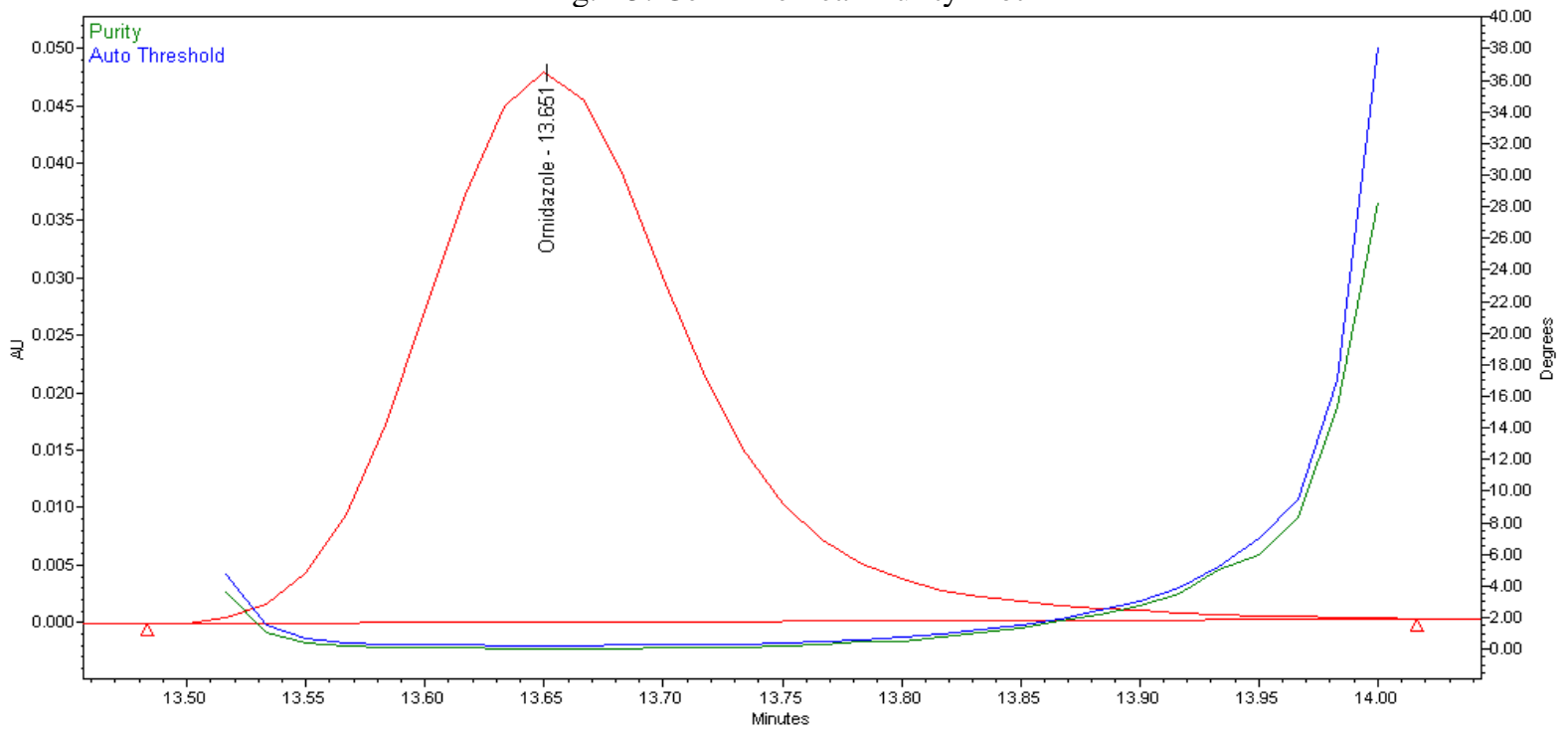

Fig.-16: Ornidazole Peak Purity Plot

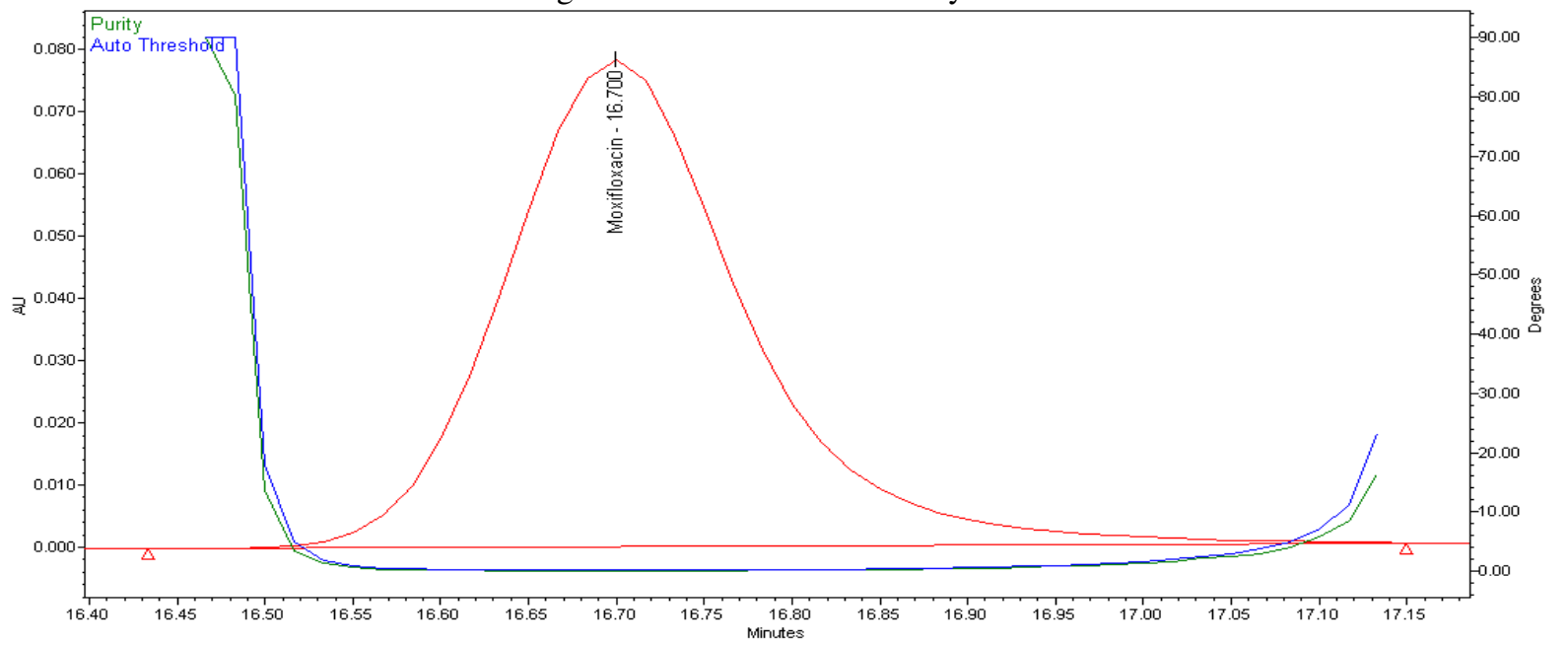

Fig.-17: Moxifloxacin Peak Purity Plot Chromatogram 
RASĀYAN $J$. Chem.

Vol. 11 | No. 4 |1696 - 1714| October - December | 2018

Table-2: System Suitability Results

\begin{tabular}{|c|c|c|c|c|c|c|}
\hline \multirow[t]{2}{*}{ Injection } & \multicolumn{3}{|c|}{ Retention time (min) } & \multicolumn{3}{|c|}{ Area } \\
\hline & Cefixime & Ornidazole & Moxifloxacin & Cefixime & \multirow{2}{*}{$\begin{array}{c}\text { Ornidazole } \\
256345\end{array}$} & Moxifloxacin \\
\hline 1. & 10.133 & 13.651 & 16.700 & 266504 & & 371025 \\
\hline 2. & 10.154 & 13.770 & 16.700 & 266125 & 256314 & 370152 \\
\hline 3. & 10.155 & 13.710 & 16.704 & 266314 & 256781 & 370145 \\
\hline 4. & 10.157 & 13.716 & 16.987 & 259987 & 254987 & 371025 \\
\hline 5. & 10.148 & 13.663 & 16.715 & 261046 & 255164 & 370146 \\
\hline$\%$ RSD & 0.10 & 0.35 & 0.75 & 1.21 & 0.31 & 0.13 \\
\hline & \multicolumn{3}{|c|}{ Theoretical plates } & \multicolumn{3}{|c|}{ Tailing factor } \\
\hline 1. & 5342 & 5468 & 5497 & 1.2 & 1.1 & 1.2 \\
\hline 2. & 5216 & 5900 & 5682 & 1.1 & 1.3 & 1.2 \\
\hline 3. & 5415 & 6102 & 5637 & 1.3 & 1.2 & 1.3 \\
\hline 4. & 5701 & 5803 & 5429 & 1.2 & 1.4 & 1.1 \\
\hline 5. & 5634 & 5269 & 5498 & 1.4 & 1.2 & 1.2 \\
\hline Average & 5461 & 5708 & 5548 & 1.24 & 1.24 & 1.20 \\
\hline \multicolumn{7}{|c|}{ Peak purity Results } \\
\hline \multirow{2}{*}{\multicolumn{2}{|c|}{$\begin{array}{c}\text { Active component } \\
\text { Cefixime }\end{array}$}} & \multicolumn{2}{|c|}{ Purity angle } & \multicolumn{2}{|c|}{ Purity threshold } & \\
\hline & & \multicolumn{2}{|c|}{$\begin{array}{l}0.310 \\
0.131\end{array}$} & 0.413 & & \\
\hline \multicolumn{2}{|c|}{ Ornidazole } & & & \multirow{2}{*}{\multicolumn{2}{|c|}{$\begin{array}{l}0.289 \\
0.256\end{array}$}} & Pass \\
\hline \multicolumn{2}{|c|}{ Moxifloxacin } & \multicolumn{2}{|c|}{0.109} & & & Pass \\
\hline
\end{tabular}

\section{Precision}

Method precision and system precision was evaluated with freshly prepared six test solutions. Intermediate precision was performed on a different instrument and different HPLC column. \%RSD of assay values was calculated and results were within the 2.0\% RSD. Figure-18 and 19 were represented the Cefixime, Ornidazole test sample and Cefixime, Moxifloxacin test sample chromatograms. Table-3 represented the precision and intermediate precision results.

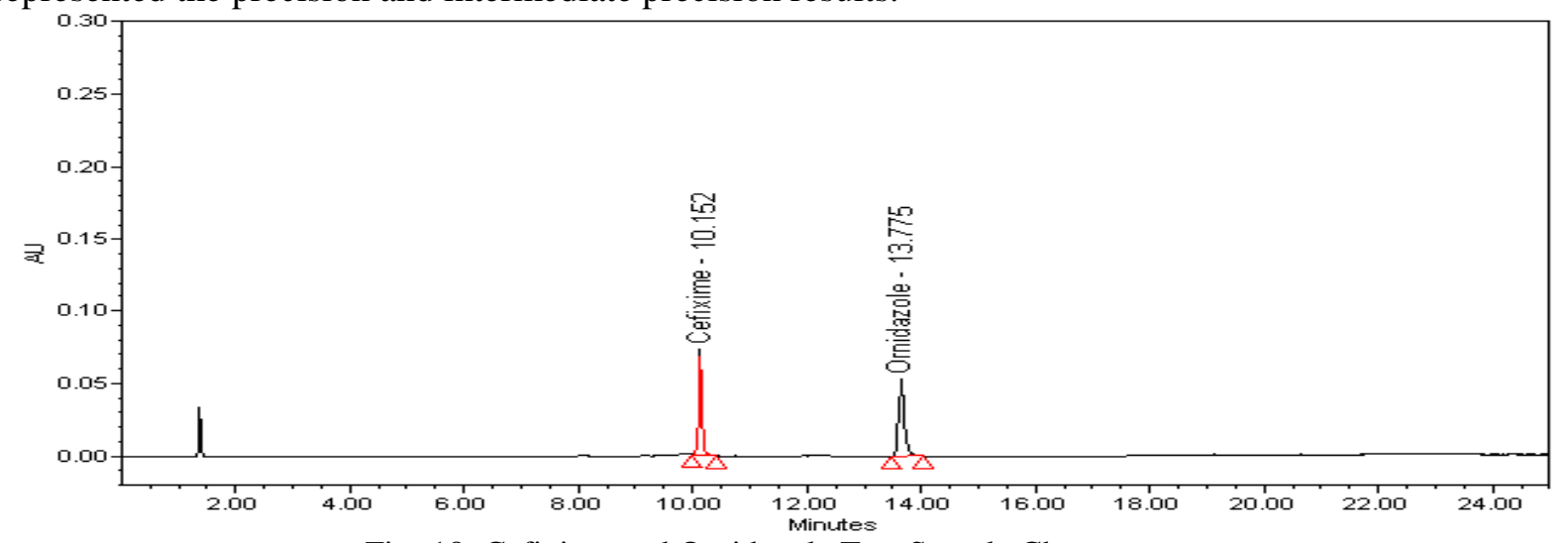

Fig.-18: Cefixime and Ornidazole Test Sample Chromatogram

Table-3: Precision and Intermediate Results

\begin{tabular}{c|c|c|c|c|c|c|c|c}
\hline \multirow{2}{*}{ S. No. } & \multicolumn{4}{|c|}{ Precision \% Assay } & \multicolumn{3}{c}{ Intermediate Precision \% Assay } \\
\cline { 2 - 8 } & Cefi. & Orni. & Cefi. & Moxi. & Cefi. & Orni. & Cefi. & Moxi. \\
\hline 1 & 99.8 & 101.2 & 100.6 & 101.3 & 101.3 & 101.2 & 101.0 & 100.6 \\
\hline 2 & 101.2 & 100.4 & 101.3 & 100.8 & 100.5 & 100.7 & 100.6 & 101.0 \\
\hline 3 & 100.6 & 101.2 & 100.4 & 100.4 & 100.6 & 100.2 & 100.4 & 101.3 \\
\hline 4 & 100.1 & 99.9 & 99.9 & 100.8 & 99.6 & 101.0 & 100.8 & 100.8 \\
\hline 5 & 99.9 & 100.1 & 100.3 & 101.4 & 100.6 & 100.7 & 99.9 & 100.4 \\
\hline 6 & 100.8 & 101.6 & 100.8 & 101.3 & 100.3 & 100.1 & 100.5 & 100.1 \\
\hline Average & 100.4 & 100.73 & 100.5 & 101 & 100.48 & 100.65 & 100.5 & 100.7 \\
\hline \% RSD & 0.55 & 0.69 & 0.47 & 0.39 & 0.55 & 0.43 & 0.37 & 0.43 \\
\hline
\end{tabular}


RASĀYAN J. Chem.

Vol. 11 | No. 4 |1696 - 1714| October - December | 2018

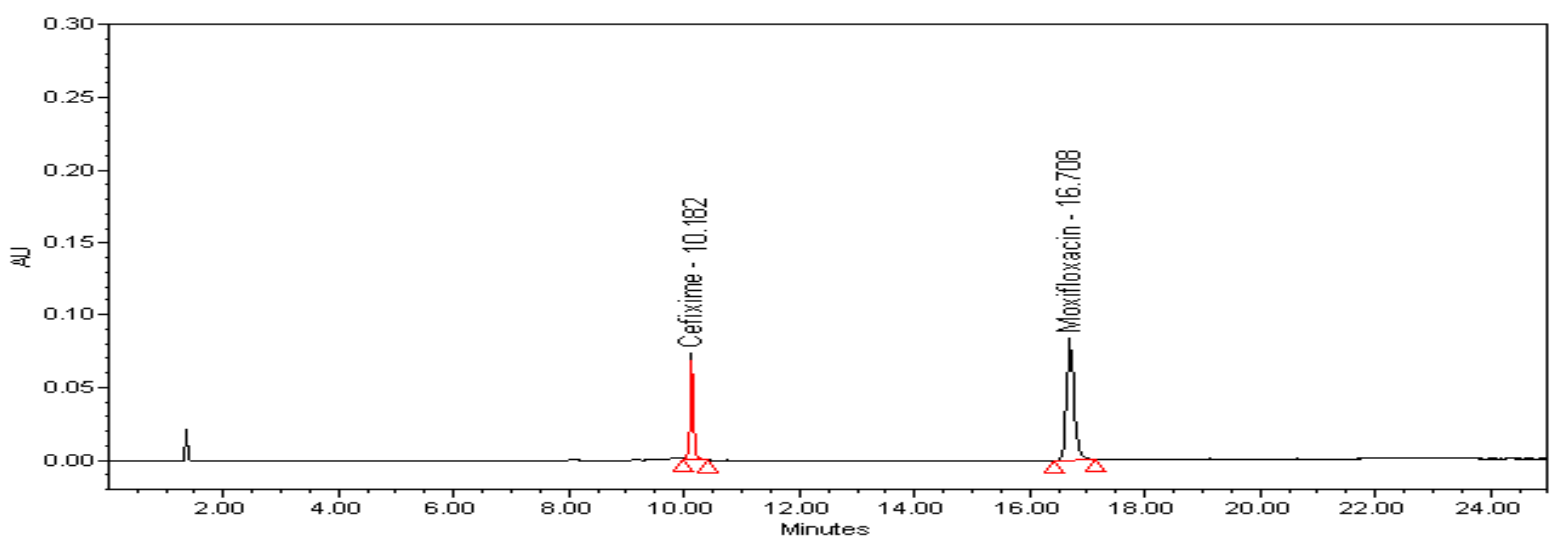

Fig.-19: Cefixime and Moxifloxacin Sample Chromatogram

\section{Specificity}

Specificity was performed to check the interference from blank, placebo, degradation studies. Acid, base, peroxide, thermal, UV and water stress study conditions were performed. Stress study conditions were listed in Table-4. Figure-20 to 31 were represented the all stress study conditions for both test samples like Cefixime - Ornidazole samples and Cefixime - Moxifloxacin samples.

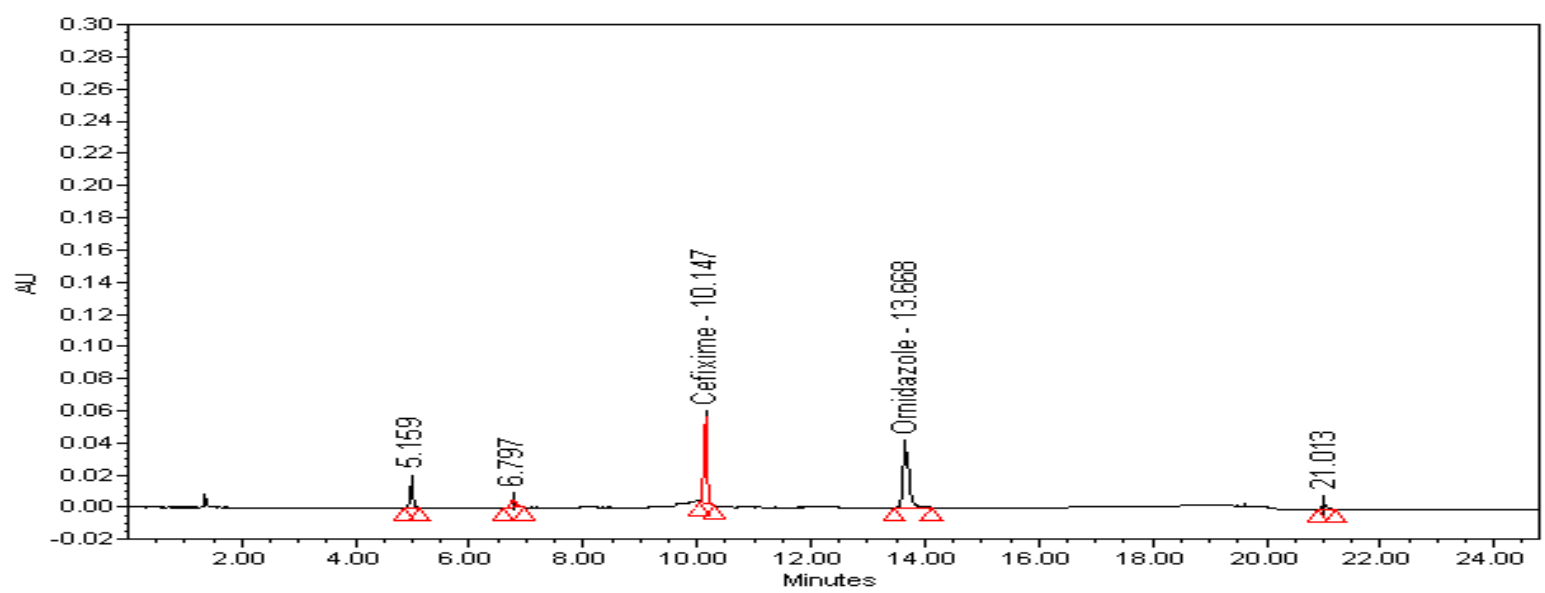

Fig.-20: Cefixime and Ornidazole Acid Stress Study Chromatogram

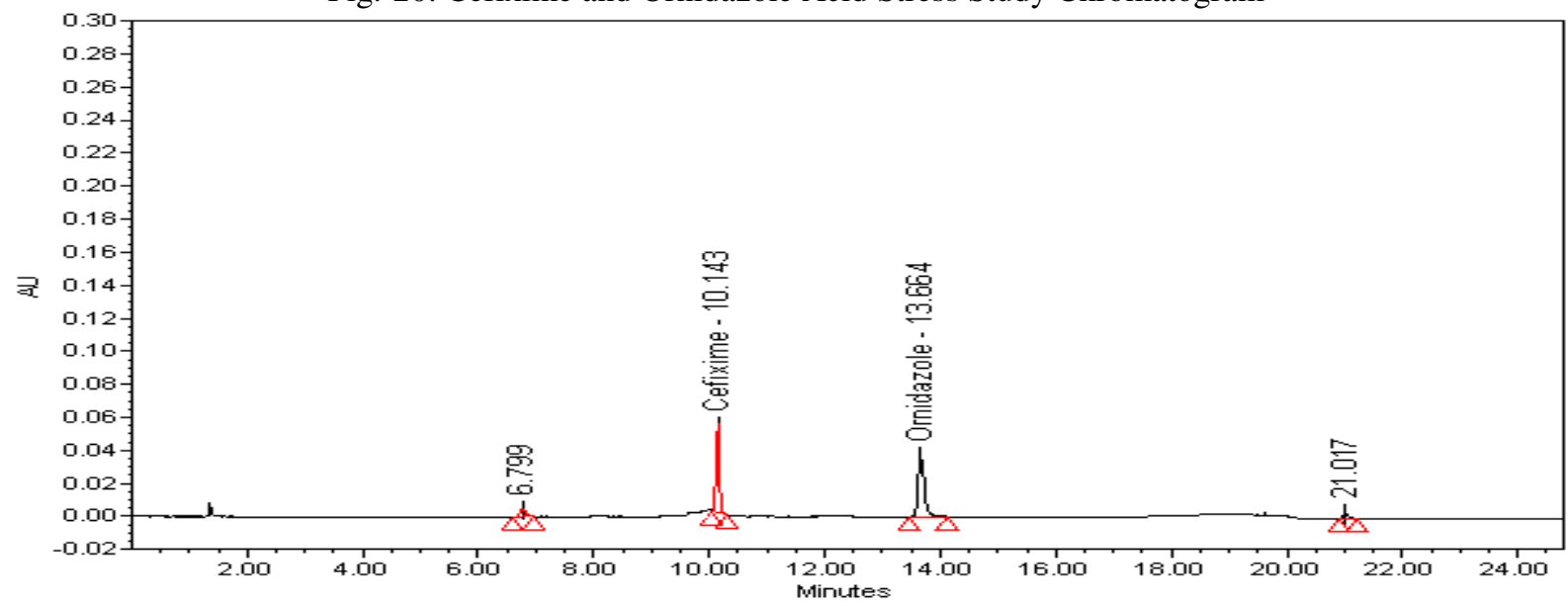

Fig.-21: Cefixime and Ornidazole Base Stress Study Chromatogram

Table-4: Specificity Stress Study Conditions

Cefixime Ornidazole Sample $\quad$ Cefixime Moxifloxacin Sample

Acid stress $/ 1 \mathrm{~N}-60^{\circ} \mathrm{C} / 60$ minutes $\quad$ Acid stress $/ 1 \mathrm{~N}-60^{\circ} \mathrm{C} / 60$ minutes


RASĀYAN J. Chem.

Vol. 11 | No. 4 | 1696 - 1714| October - December | 2018

\begin{tabular}{c|c}
\hline Base Stress $/ 1 \mathrm{~N}-60^{\circ} \mathrm{C} / 2 \mathrm{hrs}$ & Base Stress $/ 1 \mathrm{~N}-60^{\circ} \mathrm{C} / 2 \mathrm{hrs}$ \\
\hline Peroxide stress $/ 3 \%-50^{\circ} \mathrm{C} / 1 \mathrm{hrs}$ & Peroxide stress $3 \%-50^{\circ} \mathrm{C} / 1 \mathrm{hrs}$ \\
\hline Water stress- $60^{\circ} \mathrm{C} / 3 \mathrm{hrs}$ & Water stress- $60^{\circ} \mathrm{C} / 3 \mathrm{hrs}$ \\
\hline Thermal $\left(80^{\circ} \mathrm{C}\right.$ for $\left.6 \mathrm{hrs}\right)$ & Thermal $\left(80^{\circ} \mathrm{C}\right.$ for $\left.6 \mathrm{hrs}\right)$ \\
\hline UV energy of 200 -watt hrs $/{ }^{2} \mathrm{~m}$ & UV energy of 200 -watt hrs $/{ }^{2} \mathrm{~m}$ \\
\hline
\end{tabular}

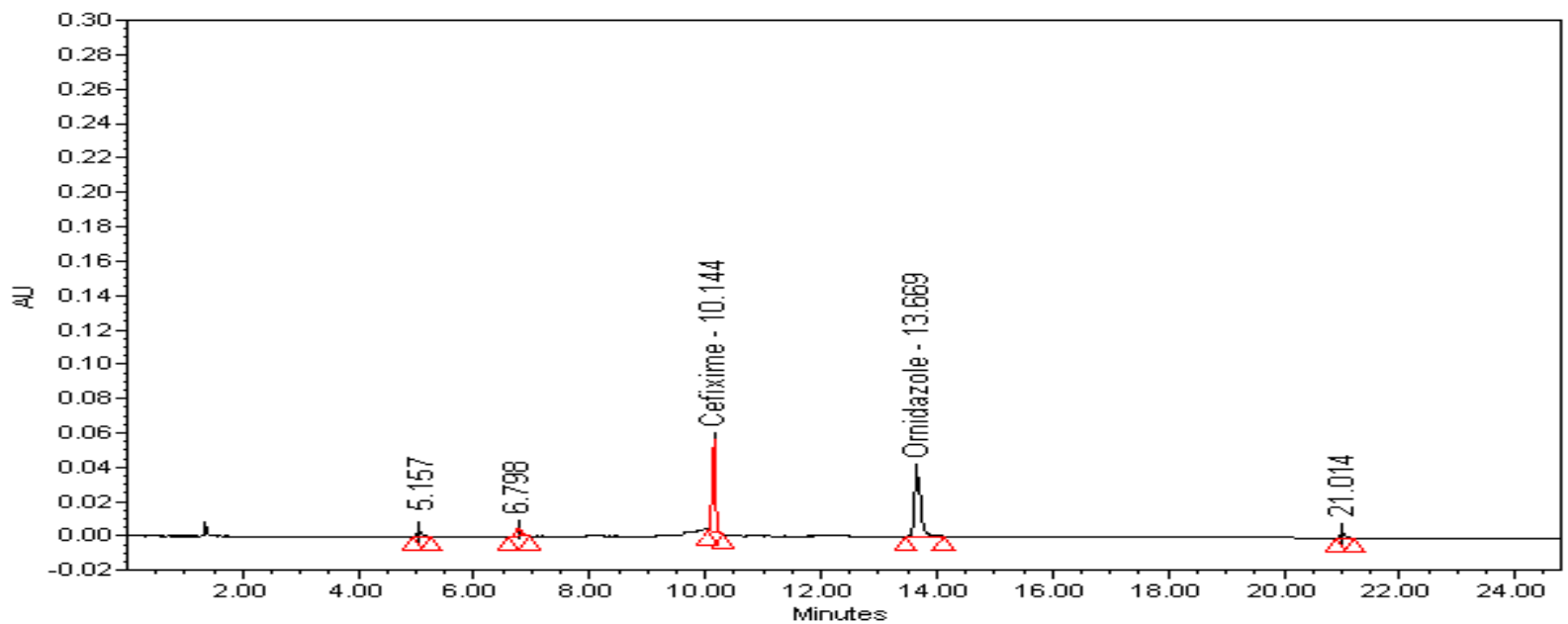

Fig.-22: Cefixime and Ornidazole Peroxide Stress Study Chromatogram

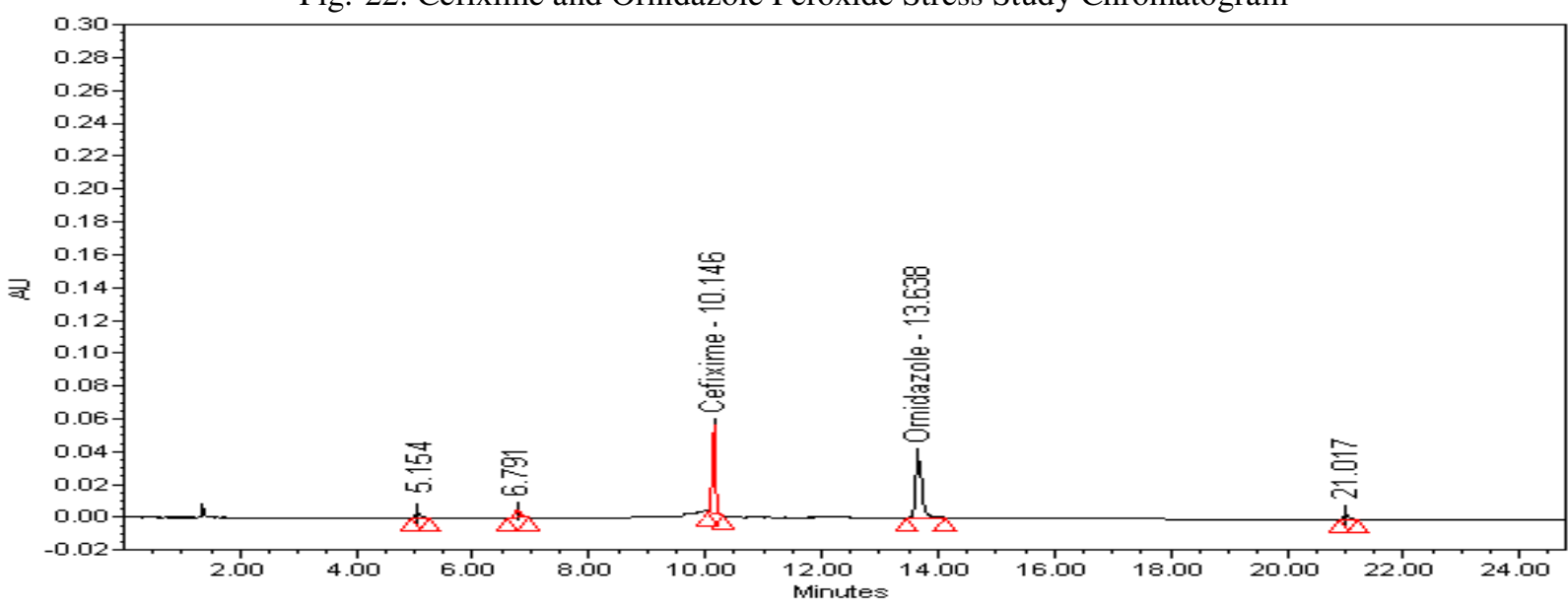

Fig.-23: Cefixime and Ornidazole Thermal Stress Study Chromatogram

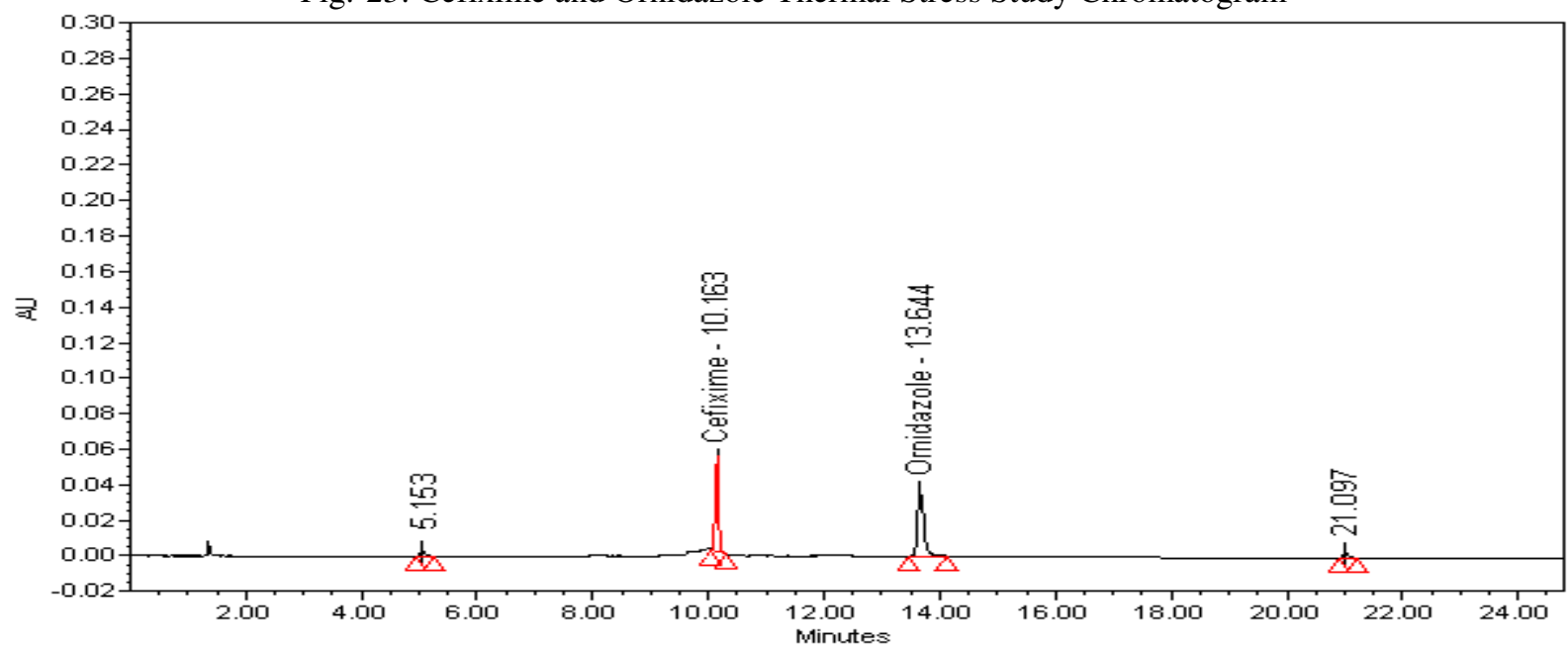

Fig.-24: Cefixime and Ornidazole UV Stress Study Chromatogram 
RASĀYAN J. Chem.

Vol. 11 | No. 4 |1696 - 1714| October - December | 2018

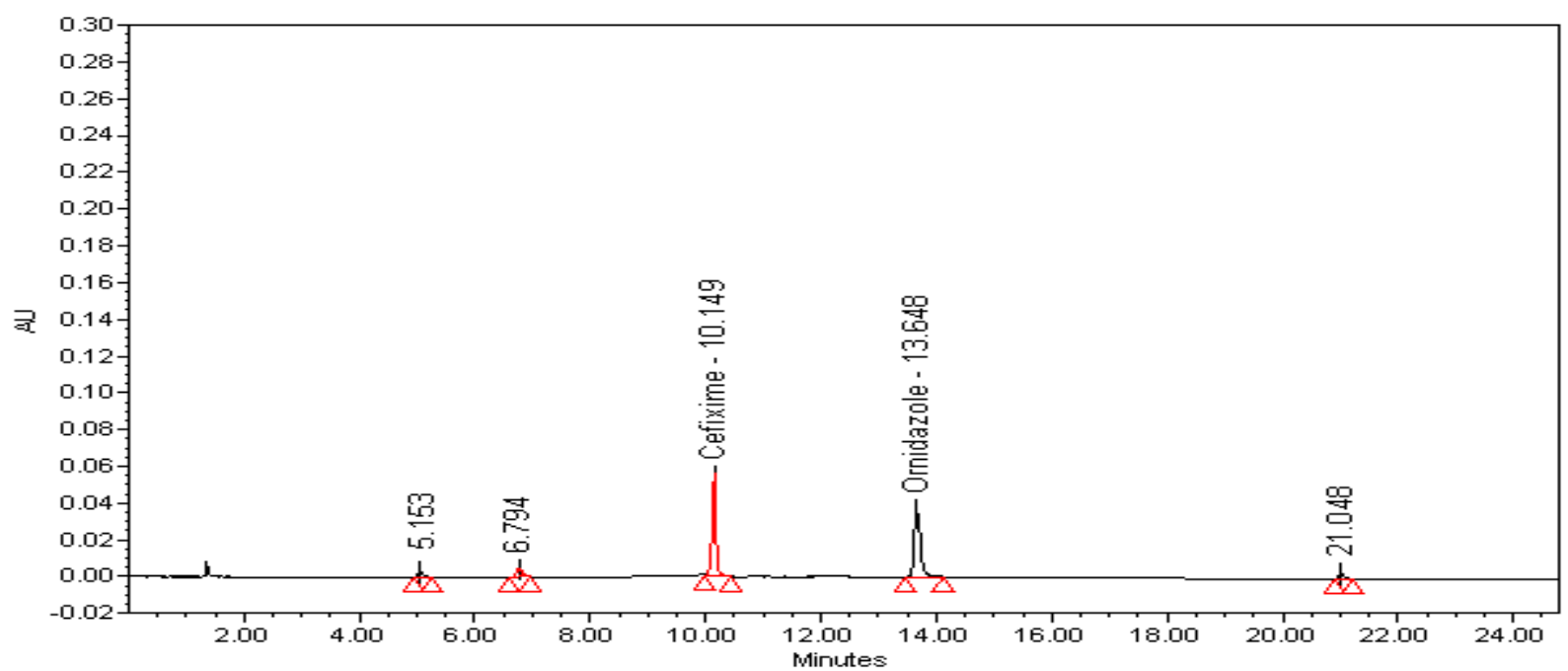

Fig.-25: Cefixime and Ornidazole Water Stress Study Chromatogram

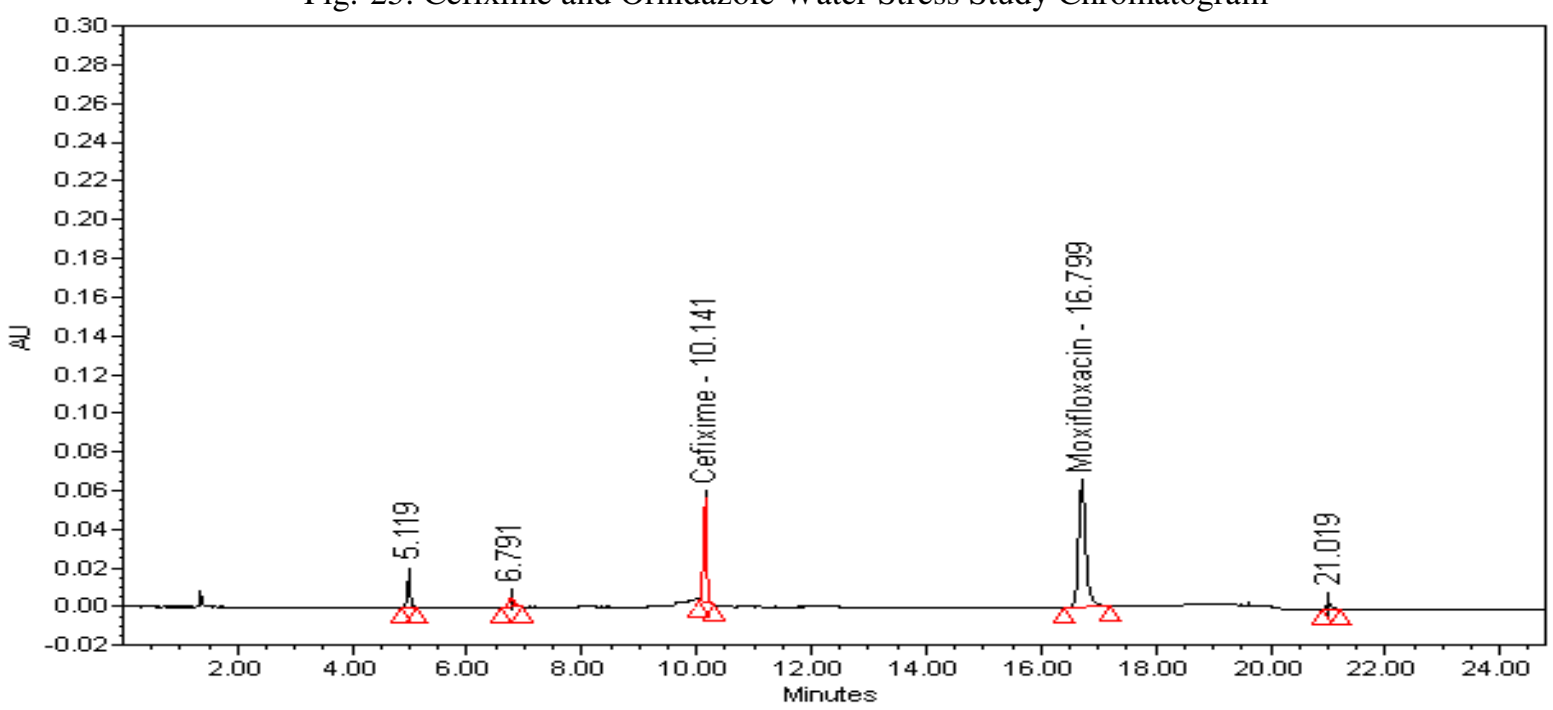

Fig.-26: Cefixime and Moxifloxacin Acid Stress Study Chromatogram

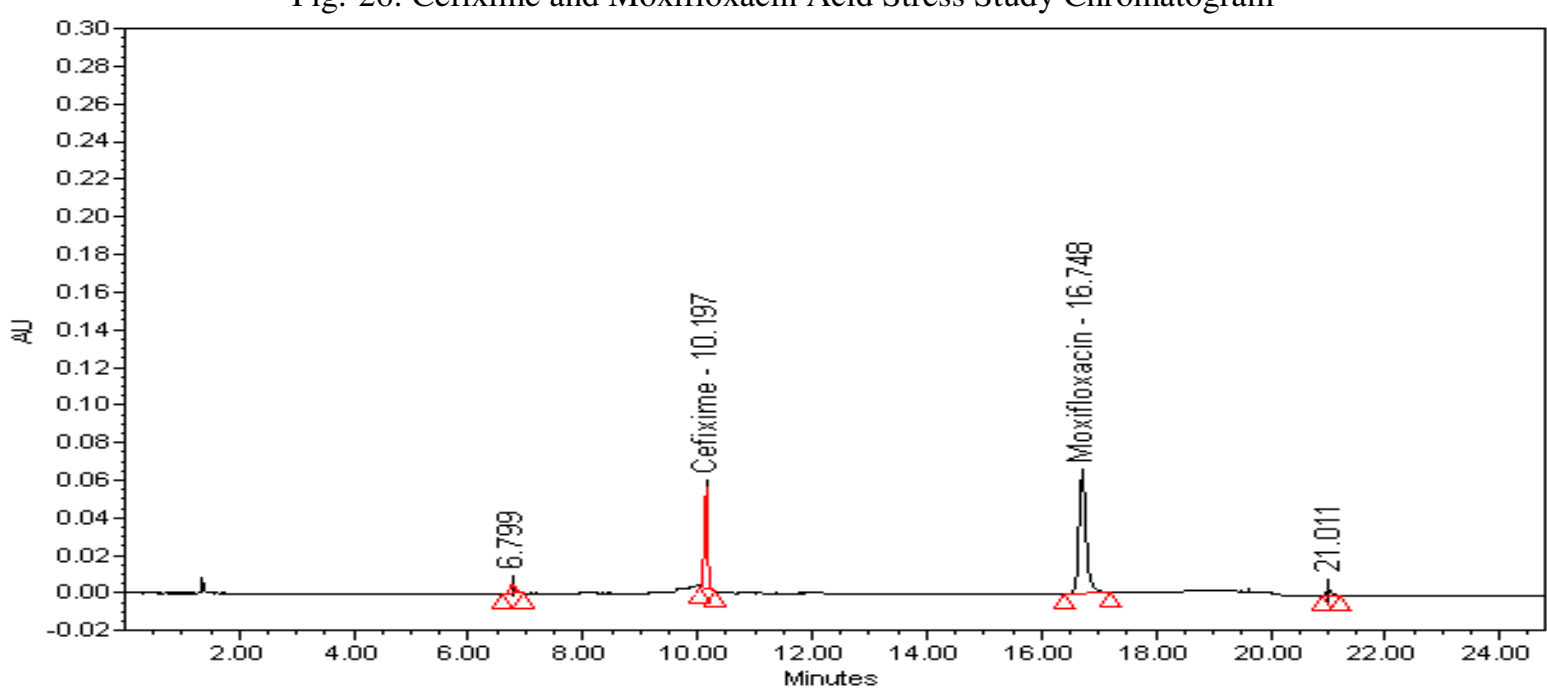

Fig.-27: Cefixime and Moxifloxacin Base Stress Study Chromatogram 
RASĀYAN J. Chem.

Vol. 11 | No. 4 |1696 - 1714| October - December | 2018

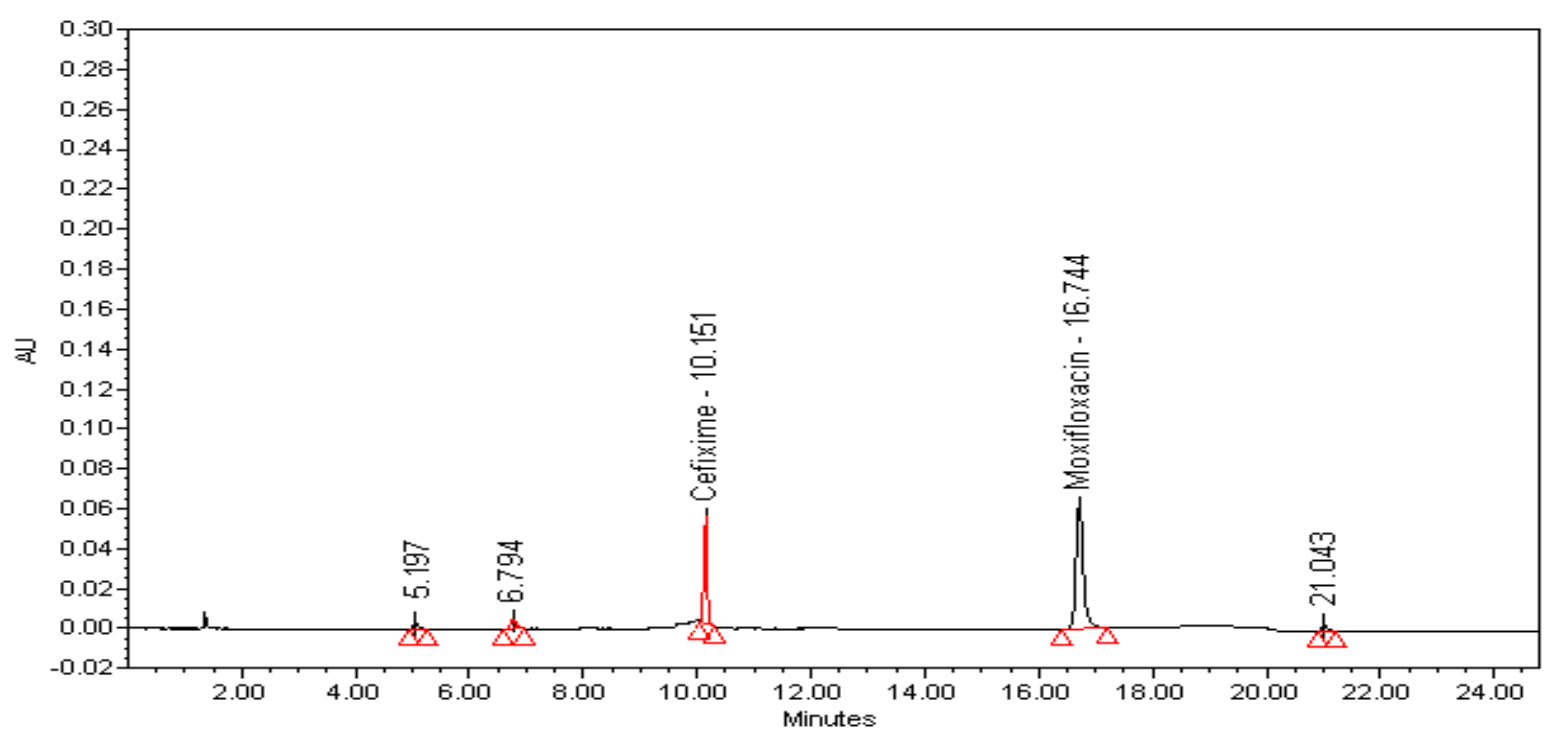

Fig.-28: Cefixime and Moxifloxacin Peroxide Stress Study Chromatogram

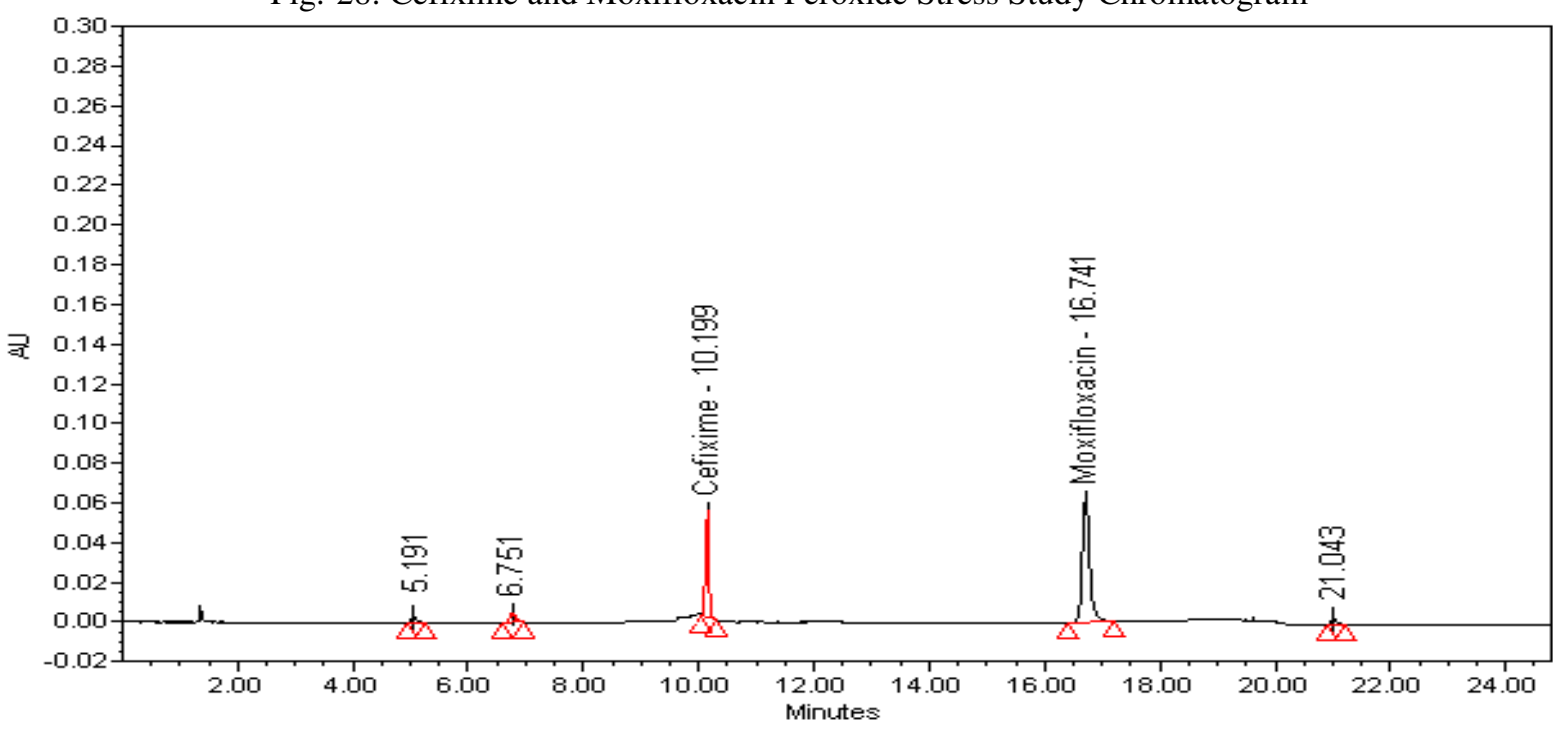

Fig.-29: Cefixime and Moxifloxacin Thermal Stress Study Chromatogram

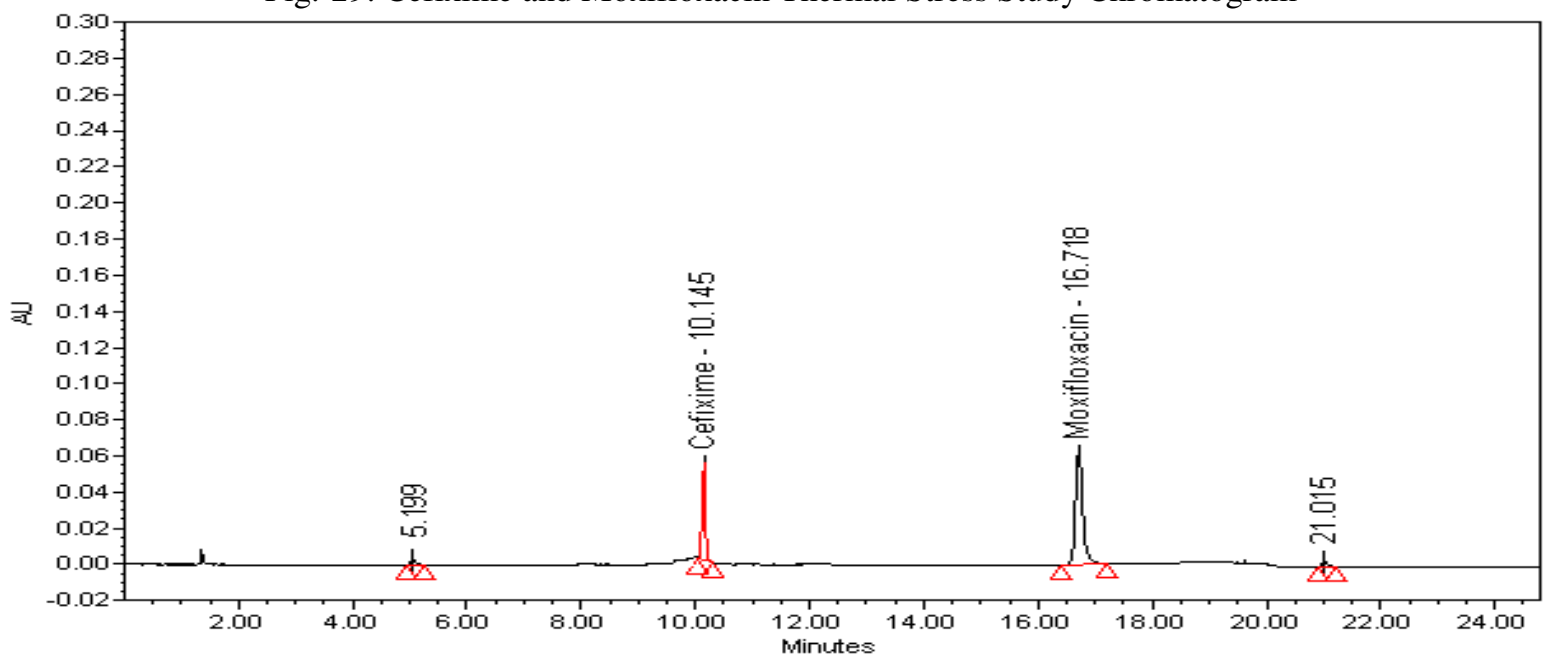

Fig.-30: Cefixime and Moxifloxacin UV Stress Study Chromatogram 
RASĀYAN J. Chem.

Vol. 11 | No. 4 |1696 - 1714| October - December | 2018

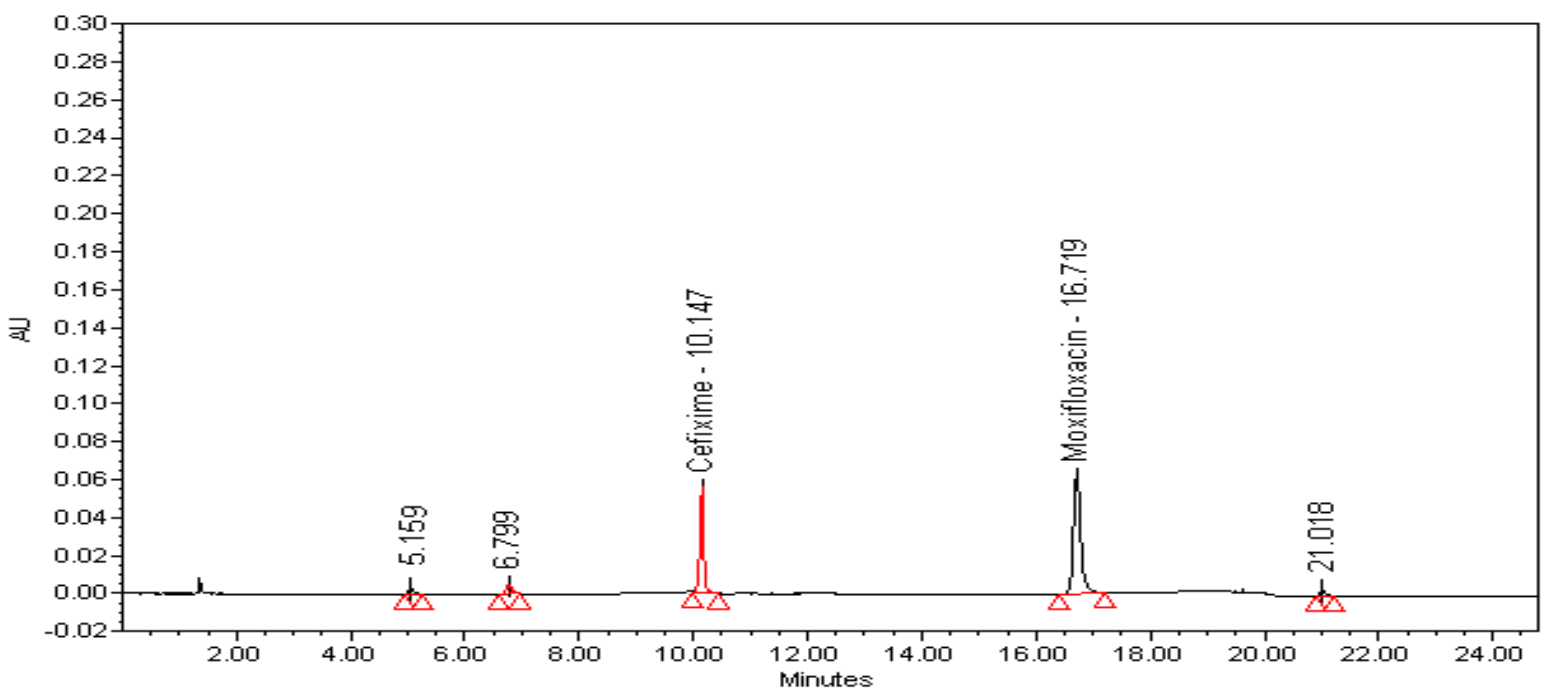

Fig.-31: Cefixime and Moxifloxacin Water Stress Study Chromatogram

Table-5: Specificity Results

\begin{tabular}{c|c|c|c|c|c|c|c|c|c}
\hline \multirow{2}{*}{$\begin{array}{c}\text { Stress } \\
\text { condition }\end{array}$} & \multicolumn{3}{|c|}{ Cefixime } & \multicolumn{3}{c|}{ Ornidazole } & \multicolumn{3}{c}{ Moxifloxacin } \\
\cline { 2 - 11 } & $\begin{array}{c}\text { Purity } \\
\text { angle }\end{array}$ & $\begin{array}{c}\text { Purity } \\
\text { threshold }\end{array}$ & $\begin{array}{c}\text { Pass/ } \\
\text { fail }\end{array}$ & $\begin{array}{c}\text { Purity } \\
\text { angle }\end{array}$ & $\begin{array}{c}\text { Purity } \\
\text { threshold }\end{array}$ & $\begin{array}{c}\text { Pass/ } \\
\text { fail }\end{array}$ & $\begin{array}{c}\text { Purity } \\
\text { angle }\end{array}$ & $\begin{array}{c}\text { Purity } \\
\text { threshold }\end{array}$ & $\begin{array}{c}\text { Pass/ } \\
\text { fail }\end{array}$ \\
\hline Acid & 0.319 & 0.412 & Pass & 0.115 & 0.261 & Pass & 0.110 & 0.231 & Pass \\
\hline Base & 0.301 & 0.431 & Pass & 0.101 & 0.271 & Pass & 0.124 & 0.246 & Pass \\
\hline Peroxide & 0.261 & 0.494 & Pass & 0.132 & 0.259 & Pass & 0.125 & 0.263 & Pass \\
\hline Thermal & 0.286 & 0.438 & Pass & 0.231 & 0.268 & Pass & 0.121 & 0.251 & Pass \\
\hline UV & 0.291 & 0.461 & Pass & 0.142 & 0.246 & Pass & 0.191 & 0.235 & Pass \\
\hline Water & 0.351 & 0.452 & Pass & 0.143 & 0.251 & Pass & 0.183 & 0.245 & Pass \\
\hline
\end{tabular}

Table-6: Specificity Results

\begin{tabular}{c|c|c|c|c|c|c}
\hline \multirow{2}{*}{$\begin{array}{c}\text { Peak RT } \\
(\mathrm{min})\end{array}$} & \multicolumn{6}{c}{ Cefixime and Ornidazole samples degradation } \\
\cline { 2 - 7 } & Acid & Base & Peroxide & Thermal & UV & Water \\
\hline 5.1 & 1.45 & NA & 1.36 & 1.30 & 1.40 & 1.34 \\
\hline 6.7 & 1.61 & 1.50 & 1.42 & 1.41 & NA & 1.40 \\
\hline 21.0 & 1.30 & 1.43 & 1.38 & 1.46 & 1.39 & 1.43 \\
\hline \multicolumn{7}{|c|}{ Cefixime and Moxifloxacin samples degradation } \\
\hline 5.1 & 1.43 & NA & 1.39 & 1.39 & 1.40 & 1.29 \\
\hline 6.7 & 1.29 & 1.38 & 1.40 & 1.42 & NA & 1.40 \\
\hline 21.0 & 1.38 & 1.42 & 1.46 & 1.40 & 1.39 & 1.38 \\
\hline
\end{tabular}

\section{Linearity}

Linearity was performed with freshly prepared different linearity level solutions. 50\%, 75\%, 100\%, 125\% and $150 \%$ linearity solutions were prepared and performed the linearity as per the ICH Q2 guidance documents. Figure-32 has represented the linearity overlay chromatograms. Figure-33 to 35 were represented the linearity graphs for Cefixime, Ornidazole, Moxifloxacin. Table-7 represented the linearity results.

Table-7: Linearity results

\begin{tabular}{c|c|c|c|c|c|c}
\hline \multirow{2}{*}{$\begin{array}{c}\text { Linearity } \\
\text { level }\end{array}$} & \multicolumn{2}{|c|}{ Cefixime } & \multicolumn{2}{c|}{ Ornidazole } & \multicolumn{2}{c}{ Moxifloxacin } \\
\cline { 2 - 7 } & Conc. & Area & Conc. & Area & Conc. & Area \\
\hline $50 \%$ & 10.2 & 89910 & 10.1 & 44521 & 10.1 & 113691 \\
\hline
\end{tabular}


RASĀYAN J. Chem.

Vol. 11 | No. 4 |1696 - 1714| October - December | 2018

\begin{tabular}{c|c|c|c|c|c|c}
\hline $75 \%$ & 15.1 & 183236 & 15.2 & 119650 & 15.0 & 225314 \\
\hline $100 \%$ & 20.1 & 286504 & 20 & 199672 & 20.2 & 363722 \\
\hline $125 \%$ & 25.3 & 395681 & 25.1 & 289631 & 25.3 & 492540 \\
\hline $150 \%$ & 30.2 & 505610 & 30.1 & 380124 & 30.0 & 625214 \\
\hline $\begin{array}{c}\text { Correlation } \\
\text { Coefficient. }\end{array}$ & \multicolumn{2}{|c|}{0.99959} & \multicolumn{2}{c}{0.99919} & \multicolumn{2}{c}{0.99945} \\
\hline
\end{tabular}

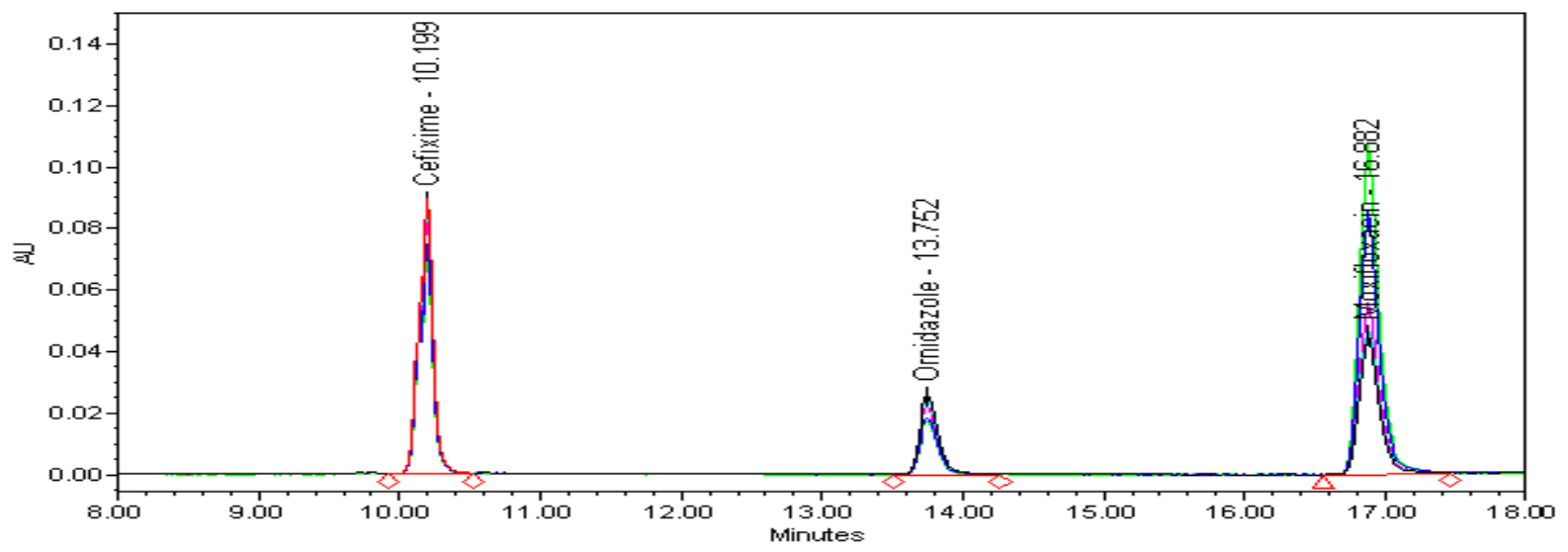

Fig.-32: Linearity Overlay Chromatogram

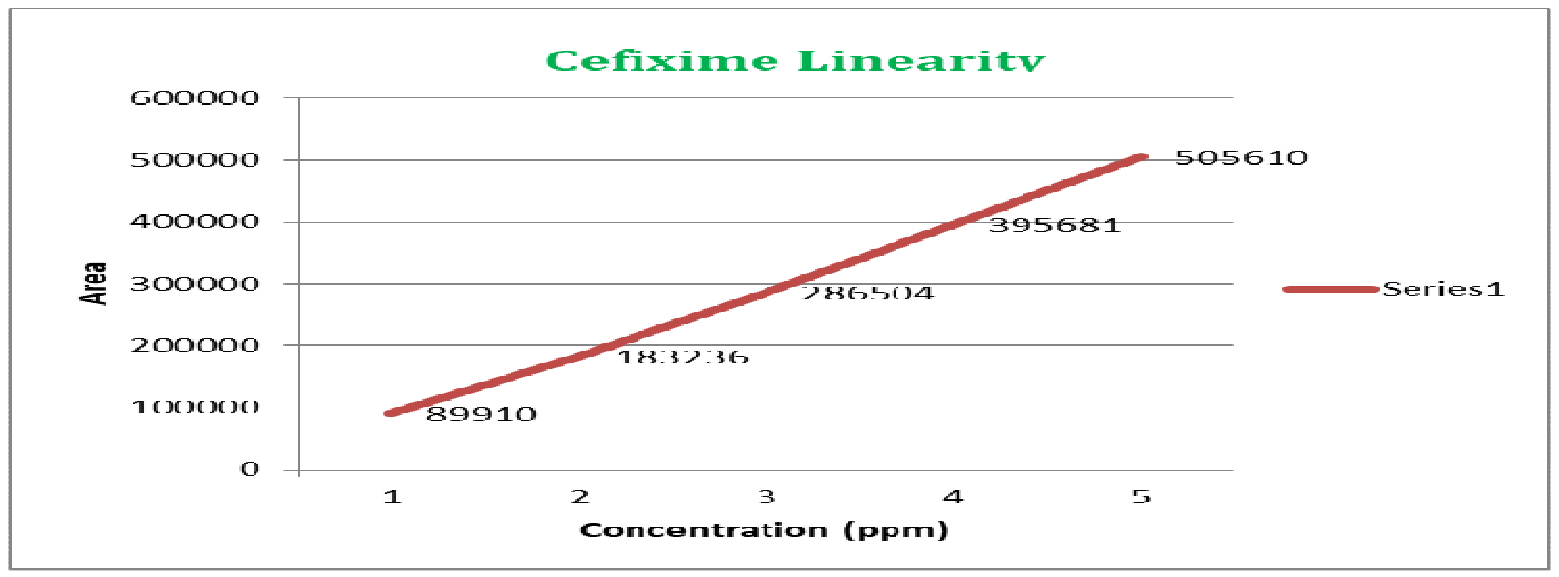

Fig.-33: Cefixime Linearity Graph

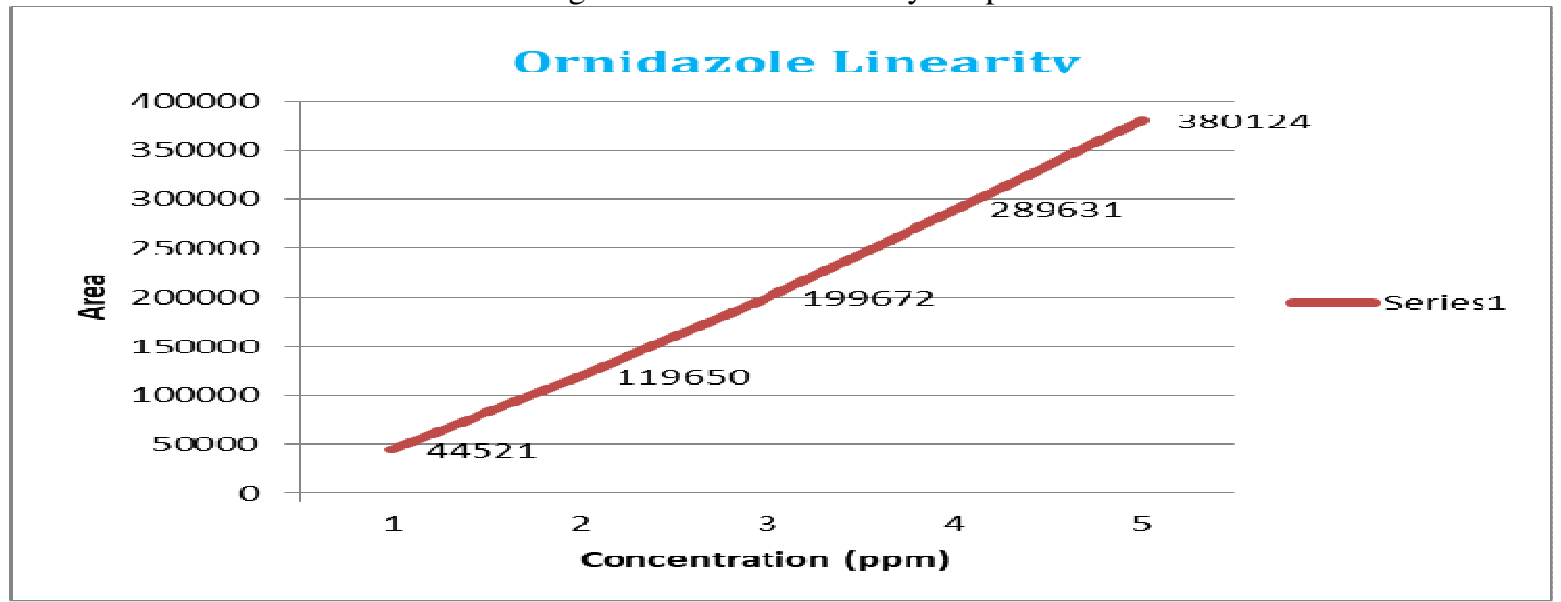

Fig.-34: Ornidazole Linearity Graph 
RASĀYAN J. Chem.

Vol. 11 | No. 4 |1696 - 1714| October - December | 2018

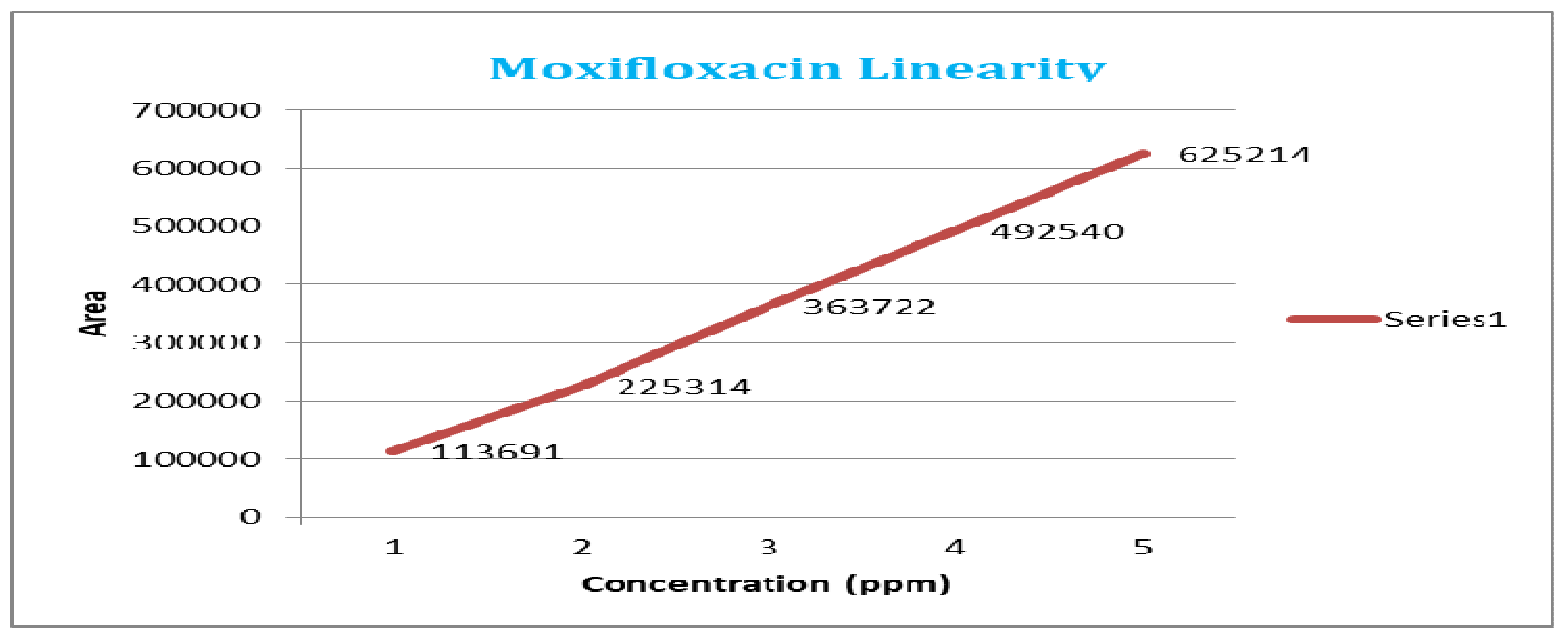

Fig.-35: Moxifloxacin Linearity Graph

\section{Accuracy}

Accuracy parameter was performed with $50 \%, 75 \%, 100 \%, 125 \%$ and $150 \%$ accuracy levels. 50\% and $150 \%$ levels were performed with six replicate preparations and the remaining $75 \%, 100 \%$ and $125 \%$ were performed with three replicate preparations. Recovery results were calculated and found to be within the acceptable limits $98 \%$ to $102 \%$. Table-7 represented the accuracy results.

Table-7: Accuracy Samples Preparations and Recovery Results

\begin{tabular}{|c|c|c|c|c|c|c|c|}
\hline \multirow[b]{2}{*}{$\begin{array}{c}\text { Recovery } \\
\text { level }\end{array}$} & \multirow[b]{2}{*}{$\begin{array}{l}\text { Sample } \\
\text { Prepn. }\end{array}$} & \multicolumn{2}{|c|}{ Cefixime Recovery } & \multicolumn{2}{|c|}{ Ornidazole Recovery } & \multicolumn{2}{|c|}{ Moxifloxacin Recovery } \\
\hline & & \% Recovery & $\begin{array}{c}\text { Mean } \\
\text { recovery/ } \\
\% \text { RSD }\end{array}$ & \% Recovery & $\begin{array}{c}\text { Mean } \\
\text { recovery/ } \\
\% \text { RSD }\end{array}$ & $\%$ Recovery & $\begin{array}{l}\text { Mean } \\
\text { recovery/ } \\
\% \mathrm{RSD}\end{array}$ \\
\hline \multirow{6}{*}{$50 \%$} & 1 & 99.6 & \multirow{6}{*}{$\begin{array}{c}100.31 / 0.5 \\
5\end{array}$} & 100.3 & \multirow{6}{*}{$\begin{array}{c}100.30 / 0.4 \\
7\end{array}$} & 100.2 & \multirow{6}{*}{$\begin{array}{c}100.40 / 0.5 \\
1\end{array}$} \\
\hline & 2 & 101.2 & & 99.7 & & 101.3 & \\
\hline & 3 & 100.3 & & 101.0 & & 100.4 & \\
\hline & 4 & 100.5 & & 100.3 & & 99.9 & \\
\hline & 5 & 99.9 & & 100.6 & & 100.0 & \\
\hline & 6 & 100.4 & & 99.9 & & 100.6 & \\
\hline \multirow{3}{*}{$75 \%$} & 1 & 100.8 & \multirow{3}{*}{$\begin{array}{c}101.06 / 0.3 \\
0\end{array}$} & 100.7 & \multirow{3}{*}{$\begin{array}{c}100.36 / 0.3 \\
5\end{array}$} & 100.1 & \multirow{3}{*}{$\begin{array}{c}100.60 / 0.4 \\
6\end{array}$} \\
\hline & 2 & 101.0 & & 100.0 & & 100.7 & \\
\hline & 3 & 101.4 & & 100.4 & & 101.0 & \\
\hline \multirow{3}{*}{$100 \%$} & 1 & 99.9 & \multirow{3}{*}{$\begin{array}{c}100.26 / 0.4 \\
0\end{array}$} & 100.6 & \multirow{3}{*}{$\begin{array}{c}100.63 / 0.3 \\
5\end{array}$} & 100.4 & \multirow{3}{*}{$\begin{array}{c}100.46 / 0.6 \\
0\end{array}$} \\
\hline & 2 & 100.2 & & 101.0 & & 101.1 & \\
\hline & 3 & 100.7 & & 100.3 & & 99.9 & \\
\hline \multirow{3}{*}{$125 \%$} & 1 & 101.0 & \multirow{3}{*}{$\begin{array}{c}100.43 / \\
0.55\end{array}$} & 100.6 & \multirow{3}{*}{$\begin{array}{c}100.63 / 0.3 \\
5\end{array}$} & 100.3 & \multirow{3}{*}{$\begin{array}{c}100.06 / 0.2 \\
1\end{array}$} \\
\hline & 2 & 100.4 & & 100.3 & & 100.0 & \\
\hline & 3 & 99.9 & & 101.0 & & 99.9 & \\
\hline \multirow{6}{*}{$150 \%$} & 1 & 100.3 & \multirow{6}{*}{$\begin{array}{c}100.48 / 0.3 \\
7\end{array}$} & 99.9 & \multirow{6}{*}{$\begin{array}{c}100.16 / 0.4 \\
4\end{array}$} & 100.4 & \multirow{6}{*}{$\begin{array}{c}100.28 / 0.3 \\
2\end{array}$} \\
\hline & 2 & 101.0 & & 100.3 & & 99.9 & \\
\hline & 3 & 100.7 & & 101.0 & & 100.3 & \\
\hline & 4 & 100.6 & & 100.1 & & 100.8 & \\
\hline & 5 & 100.4 & & 99.9 & & 100.0 & \\
\hline & 6 & 99.9 & & 99.8 & & 100.3 & \\
\hline
\end{tabular}

\section{Ruggedness}

Ruggedness was performed for standard and sample solutions at refrigerator and room temperature conditions. Initially prepared two samples were kept at refrigerator and room temperature and performed the analysis at $12 \mathrm{hr}$ and $36 \mathrm{hrs}$. Table- 8 represented the solution stability results. 
RASĀYAN $J$. Chem.

Vol. 11 | No. 4 |1696 - 1714| October - December | 2018

Table-8: Sample Solution Stability Results

Room Temperature

\begin{tabular}{|c|c|c|c|c|c|c|c|c|}
\hline \multirow{3}{*}{$\begin{array}{c}\text { Time } \\
\text { interval }\end{array}$} & \multicolumn{4}{|c|}{ Cefixime Ornidazole Sample } & \multicolumn{4}{|c|}{ Cefixime Moxifloxacin Sample } \\
\hline & \multicolumn{2}{|c|}{ Cefixime } & \multicolumn{2}{|c|}{ Ornidazole } & \multicolumn{2}{|c|}{ Cefixime } & \multicolumn{2}{|c|}{ Moxifloxacin } \\
\hline & $\%$ Assay & $\%$ Diff. & $\%$ Assay & $\%$ Diff. & $\%$ Assay & $\%$ Diff. & $\%$ Assay & $\%$ Diff. \\
\hline Initial-1 & 100.8 & \multirow{2}{*}{ NA } & 100.0 & \multirow{2}{*}{ NA } & 100.6 & \multirow{2}{*}{ NA } & 99.9 & \multirow{2}{*}{ NA } \\
\hline Intial-2 & 100.2 & & 100.2 & & 100.3 & & 100.1 & \\
\hline 12 hrs- 1 & 100.2 & 0.6 & 100.4 & -0.4 & 100.9 & -0.3 & 100.3 & -0.4 \\
\hline 12 hrs-2 & 100.4 & -0.2 & 100.8 & -0.6 & 100.0 & 0.3 & 100.6 & -0.5 \\
\hline 36 hrs- 1 & 101.1 & -0.3 & 101.0 & -1.0 & 100.4 & 0.2 & 100.0 & -0.1 \\
\hline $36 \mathrm{hrs}-2$ & 100.5 & -0.3 & 100.6 & -0.4 & 100.6 & -0.3 & 100.5 & -0.4 \\
\hline
\end{tabular}

Robustness

Robustness was evaluated for mobile phase flow rate, column oven temperature variations. System suitability results were calculated and results were within the acceptable limits. Table- 9 represented the robustness results.

Table-9: Flow Rate Variation, Temperature Variation System Suitability Results

\begin{tabular}{|c|c|c|c|c|c|c|}
\hline Variation & $\begin{array}{c}\text { Robust } \\
\text { Parameters }\end{array}$ & & $\mathrm{RT}(\min )$ & $\begin{array}{c}5 \text { inj. Area } \\
\% \text { RSD }\end{array}$ & $\begin{array}{l}\text { USP Plate } \\
\text { Count avg. }\end{array}$ & $\begin{array}{c}\text { USP Tailing } \\
\text { avg. }\end{array}$ \\
\hline \multirow{9}{*}{$\begin{array}{c}\text { Flow } \\
\text { Variation }\end{array}$} & \multirow{3}{*}{$\begin{array}{c}\text { Actual } \\
(1.0 \mathrm{ml} / \mathrm{min})\end{array}$} & Cefi. & 10.14 & 0.32 & 5681 & 1.12 \\
\hline & & Orni. & 13.60 & 0.25 & 5490 & 1.01 \\
\hline & & Moxi. & 16.70 & 0.21 & 5389 & 1.10 \\
\hline & \multirow{3}{*}{$\begin{array}{c}\text { Low } \\
(0.9 \mathrm{ml} / \mathrm{min})\end{array}$} & Cefi. & 10.23 & 0.40 & 5709 & 1.30 \\
\hline & & Orni. & 13.81 & 0.34 & 6100 & 1.41 \\
\hline & & Moxi. & 16.91 & 0.29 & 6081 & 1.13 \\
\hline & \multirow{3}{*}{$\begin{array}{c}\text { High } \\
(1.1 \mathrm{ml} / \mathrm{min})\end{array}$} & Cefi. & 9.95 & 0.32 & 5937 & 1.10 \\
\hline & & Orni. & 12.96 & 0.41 & 5890 & 1.15 \\
\hline & & Moxi. & 16.01 & 0.29 & 5687 & 1.31 \\
\hline \multirow{6}{*}{$\begin{array}{c}\text { Column } \\
\text { Oven Temp. }\end{array}$} & \multirow[t]{3}{*}{ Low $25^{\circ} \mathrm{C}$} & Cefi. & 10.42 & 0.31 & 5909 & 1.25 \\
\hline & & Orni. & 13.91 & 0.28 & 6012 & 1.01 \\
\hline & & Moxi. & 16.98 & 0.43 & 6081 & 1.15 \\
\hline & \multirow[t]{3}{*}{ High $35^{\circ} \mathrm{C}$} & Cefi. & 10.10 & 0.40 & 5964 & 1.12 \\
\hline & & Orni. & 13.25 & 0.36 & 5937 & 1.32 \\
\hline & & Moxi. & 16.34 & 0.30 & 6106 & 1.30 \\
\hline
\end{tabular}

\section{CONCLUSION}

Cefixime, Ornidazole and Moxifloxacin three components doesn't have the single HPLC method. Our objective was achieved with simple RP-HPLC method for the determination of three components in the single method. Optimized method was validated as per the ICH Q2 guidance with precision, accuracy, linearity, specificity, ruggedness and robustness. Validation parameters results found to be good and within the acceptable results. Hence, this method can be considered as stability indicating and used for routine quality evaluation of medicinal products.

\section{REFERENCES}

1. M. Unemo, D. Golparian, R. Nicholas, M. Ohnishi, A. Gallay, P. Sednaoui, Antimicrobial Agents and Chemotherapy, 56(3), 1273(2012).

2. S. Yokoi, T. Deguchi, T. Ozawa, M. Yasuda, S.I. Ito, Y. Kubota, M. Tamaki, S. I. Maeda, Emerging Infectious Diseases, 13(8), 1275(2007).

3. R. Jain, V.K.Gupta, N. Jadon, K. Radhapyari, Analytical Biochemistry, 407(1), 79(2010)

4. C. A. Ison, J. Hussey, K. N. Sankar, J. Evans, S. Alexander, Eurosurveillance, 16(14), 19833(2011).

5. S. Eric-Jovanovic, D. Agbaba, D. Zivanov-Stakic, S. Vladimirov, Journal of Pharmaceutical and Biomedical Analysis, 18(4-5), 893(1998). 
6. P. Rutgeerts, G. Van Assche, S. Vermeire, G. D’Haens, F. Baert, M. Noman, I. Aerden, G. De Hertogh, K. Geboes, M. Hiele, A. D'Hoore, Gastroenterology, 128(4), 856(2005).

7. S.S. Vaghani, M. M. Patel, C. S. Satish, Carbohydrate Research, 347(1), 76(2012).

8. G. Oberländer, C.H.Yeung, T.G.Cooper, Journal of Reproduction and Fertility, 100(2), 551(1994).

9. W. Bone, N. G. Jones, G. Kamp, C.H.Yeung, T. G. Cooper, Journal of Reproduction and Fertility, 118(1), 127(2000).

10. A. Wagenfeld, C.H.Yeung, K. Strupat, T.G.Cooper, Biology of Reproduction, 58(5), 1257(1998).

11. M. B. Conde, A. Efron, C. Loredo, G. R. De Souza, N. P. Graça, M. C. Cezar, M. Ram, M. A. Chaudhary, W. R. Bishai, A. L. Kritski, R. E. Chaisson, The Lancet, 373(9670), 1183(2009).

12. H. Stass, A. Dalhoff, D. Kubitza, U. Schühly, Antimicrobial Agents and Chemotherapy, 42(8), 2060(1998).

13. E. L. Nuermberger, T. Yoshimatsu, S. Tyagi, R. J. O'Brien, A. N. Vernon, R. E. Chaisson, W. R. Bishai, J. H. Grosset, American Journal of Respiratory and Critical Care Medicine, 169(3), 421(2004).

14. W. J. Burman, S. Goldberg, J. L. Johnson, G. Muzanye, M. Engle, A. W. Mosher, S. Choudhri, C. L. Daley, S. S. Munsiff, Z. Zhao, A. Vernon, American Journal of Respiratory and Critical Care Medicine, 174(3), 331(2006).

15. H. Stass, D. Kubitza, Journal of Antimicrobial Chemotherapy, 43(2), 83(1999).

16. R. K. Nanda, J. Gaikwad, A. Prakash, Journal of Pharmacy Research, 2(7), (2009)

17. G. J. Kher, V. R. Ram, G. G. Pandiya, H. S. Joshi, International Journal of ChemTech Research, 4(3), 1124(2012).

18. G. S. Devika, M. Sudhakar, J. Venkateshwara Rao, Der Pharma Chemica, 2(6), 97(2010).

19. R. K. Patel, R. R. Parmar, V. M. Patel, D. A. Shah, Int. J. Pharm. Res. Bio-Sci., 2, 81(2012).

20. G. S. Devika, M. Sudhakar, J. V. Rao, Orient J. Chem., 28(4), 1743(2012).

21. S. R. Shah, P. Pradhan, S. Dey, Int. J. PharmTech Res., 5(1), 198(2013).

22. M. I. Anees, M. S. Baig, A. Tathe, World Journal of Pharmacy and Pharmaceutical Sciences, 4(3), 1172(2015).

23. M. Patel, J. Kakadiya, N. Shah, Asian Journal of Pharmaceutical Science and Thechnology, 3(1), 19(2013).

24. C. K. Shah, Global Research Journal of Pharmaceutical Sciences, 1(1), 19(2012).

25. R. Kant, R. Bodla, R. Bhutani, G. Kapoor, International Journal of Pharmacy and Pharmaceutical Sciences, 7(9), 316(2015).

26. M. Nageswara Rao, P. R. K. Vein and B. Haribabu, Rasayan Journal of Chemistry, 8(4), 477(2015).

27. K. Kiran Kumar and R. Venkata Nadh, Rasayan Journal of Chemistry, 4(4), 863(2011).

28. K. Kathiresan, R. Murgugan, M. Shahul Hameed, Gokula Inimai and Taranath Kanyadhara, Rasayan Journal of Chemistry, 2(3), 588(2009).

[RJC-4093/2018] 